\title{
Electric Vehicle Charging Implications for Utility Ratemaking in Colorado
}

David Hurlbut, Joyce McLaren, Sam Koebrich, Juliana Williams, and Emily Chen

Background Research for Colorado Public Utilities Commission 


\section{Contents}

1 Questions and Insights

2 State of EV Research

3 Colorado EV Load Model

4 Utility EV Pilots and Rates

5 EV Charger Technology

6 Public Direct-Current Fast Charging (DCFC)

7 Fleet Charging

8 Insights (Recap) 
1. Questions and Insights

Quick Summary 


\section{System impacts of charging behaviors}

- What EV charging behaviors might systematically increase or decrease the utility's cost of service in Colorado?

- Charging during periods with low system cost

- The ability to vary charging load up or down in the evening to balance load and maintain system stability

- What is the difference between natural (unincentivized) EV charging patterns and charging patterns that minimize the cost of electricity service?

- Time-of-use (TOU) rates would likely mitigate peak load growth by shifting charging load to low-cost hours

- However, the 9 p.m. TOU transition period could result in a new evening peak as well as a brief but steep demand ramp, if EV adoption is high and charging is not spread out 


\section{System impacts of charging behaviors}

- How would load profiles change if they reflected reasonably achievable behaviors that reduced the cost of service?

- Controlled charging, if used extensively and if EV adoption were high, might mitigate the tendency for a new peak to form under existing TOU rates 


\section{Getting ready}

- Are there "make-ready" investments by the utility that might encourage desirable load growth for EV charging?

- High-density residential buildings (condos and apartments) are a potential focus area where EV demand might currently be suppressed due to the lack of L2 (240v) charging capability

- A review of PUC rules that govern master metering could

- identify possible amendments specific to EV charging in multifamily residences, and

- inform the design of utility programs to target make-ready investments in multifamily developments where the chances of both EV use and cost recovery are high 


\section{At-work charging}

- What effect could electricity rates have on at-work charging?

- At-work charging makes up a small portion of total EV charging, so the system benefits are likely to be small

- Company policies affecting at-work EV charging (free vs fee, open vs assigned spaces) are outside the sphere of electricity rate making 


\section{Main areas of EV research and analysis}

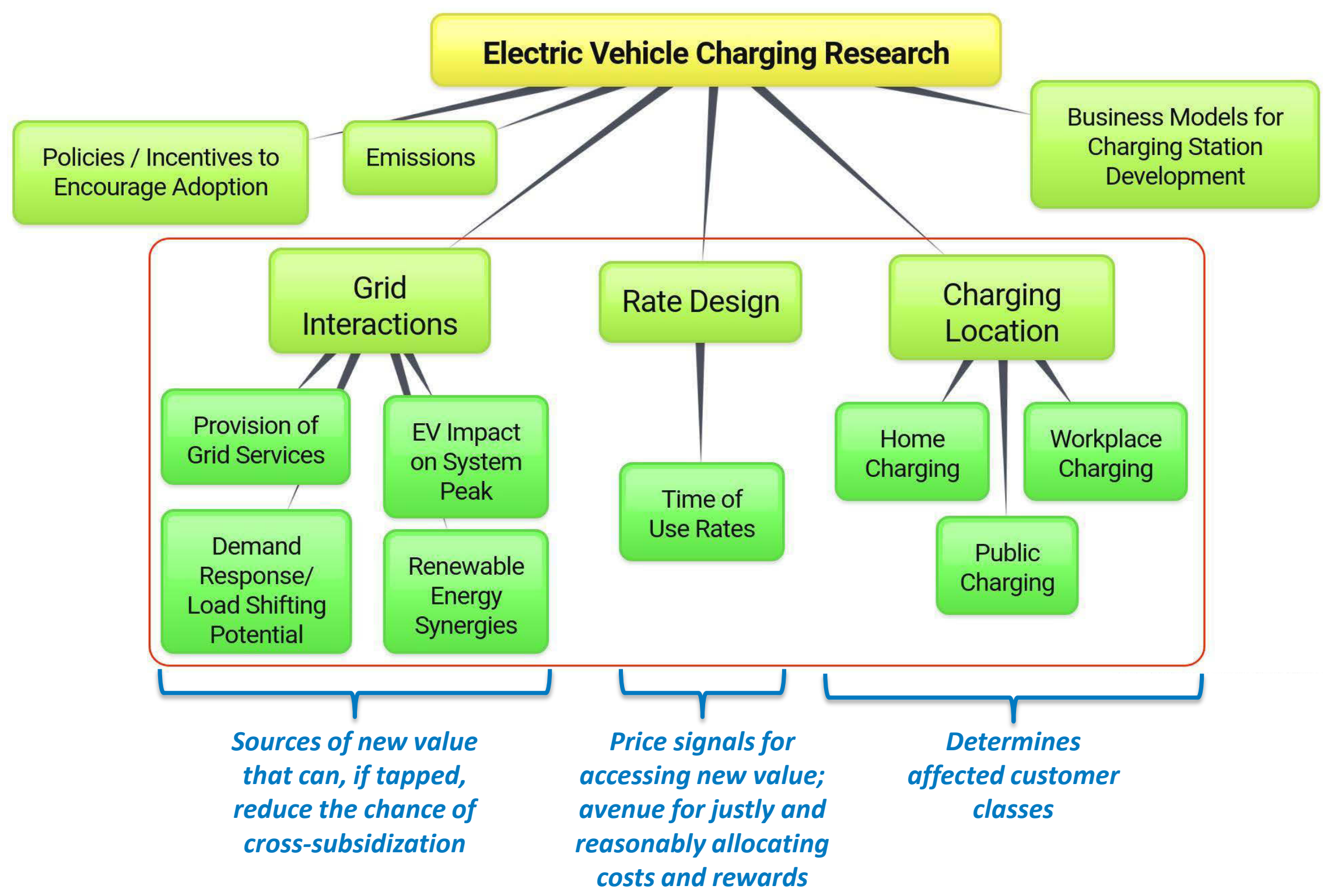




\section{Most EV charging happens at home}

At present, the tendency is for more than $80 \%$ of EV charging load (and as much as $93 \%$ under some scenarios) to happen at home, mostly in the evening. The rest is divided between public charging and workplace charging.

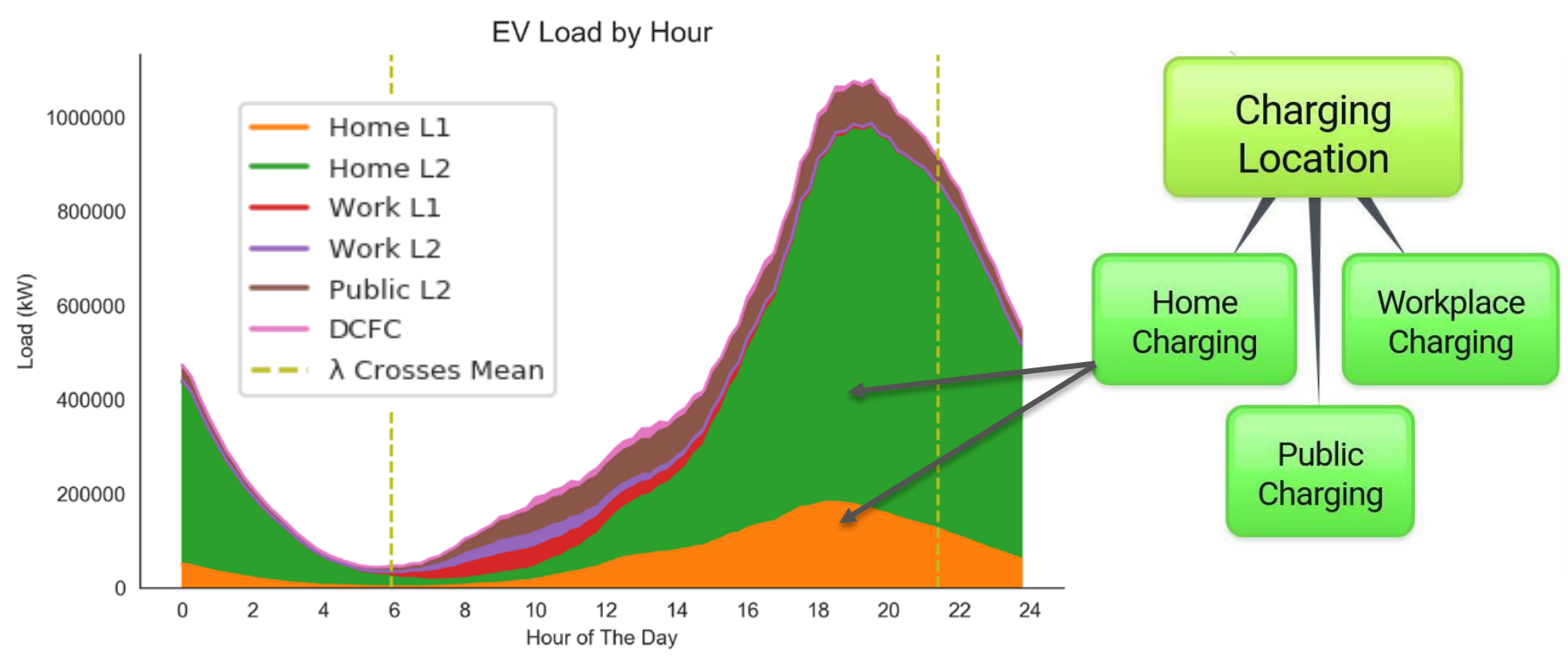

Hours when system cost is above the daily mean

NREL simulation for Colorado using EVI-Pro, with electricity costs from Colorado utility rate books 


\section{Unknown: EVs and multifamily residential customers}

- Known: The income bracket known to purchase the most EVs includes many who live in multifamily housing.

- Regulatory question: Do submetering rules affect infrastructure for EV charging in multifamily housing, and could this affect EV demand?

Multifamily housing by income (\% of all housing)

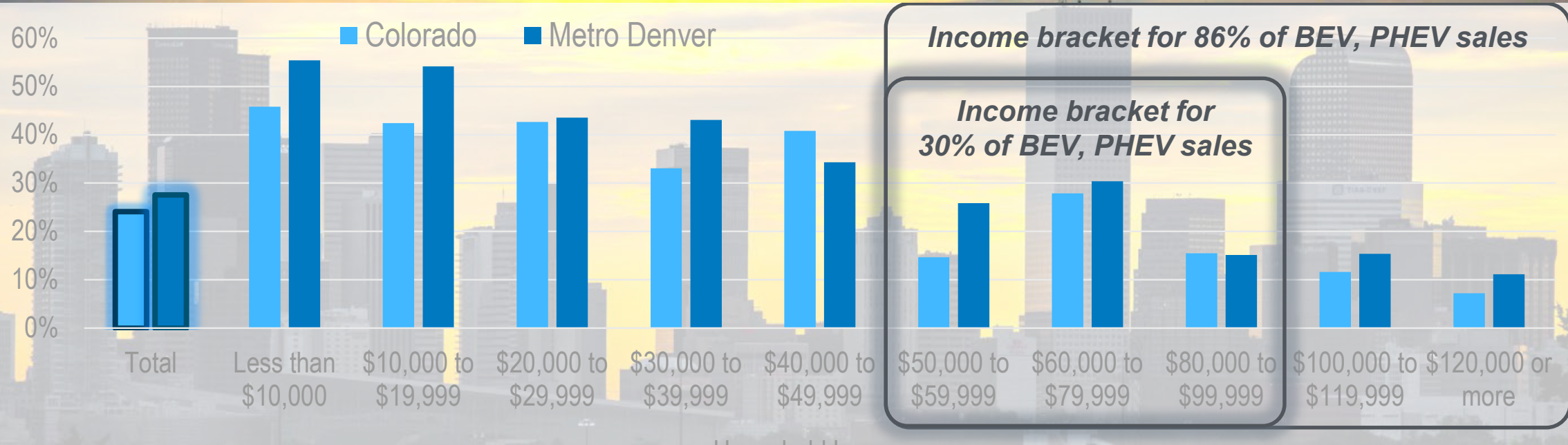

Household Income

(Muehlegger and Rapson; U.S. Census Bureau, American Housing Survey. Photo by Dennis Schroeder, NREL 27455) 


\section{Other current gaps in EV research}

- Alternative business models for charging stations

- Financing models for charging stations

- Impact of range anxiety on economics of public charging stations (and, ultimately, on EV purchase decisions)

- Number, type, and distribution of chargers needed to support rollout of EVs

- NREL's EVI-Pro model was developed to help answer these questions 


\section{Major existential gap}

- The behaviors we observe in today's nascent EV market might change as the market matures

- Example: No way to know empirically today whether home charging will continue to dominate 10 years from now

- Example: Cost of L2 "smart" chargers in the event of increased demand for control functions

- The value of looking at today's phenomena is to form questions, recognizing that the answers might change as EVs become mainstream 
3. Colorado EV Load Model

3. Colorado EV Load Model

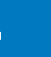




\section{Key Insights: EV adoption scenario analysis}

- Absent systemic changes in customer behavior, the vast majority of EV charging will occur at home. Without an incentive or disincentive in place, this charging may significantly contribute to system peak demand.

- While existing TOU rates could incentivize EV owners to delay their charging, without staggering this charging, new daily peaks can emerge under the Colorado Energy Office's (CEO) medium and high adoption scenarios.

- Demand response (DR) can be used to distribute the overnight charging of EVs during times when the cost of energy is less expensive to flatten the daily load profile.

- An advanced deployment of demand response could use a network of EV home chargers to respond to wind ramping. 


\section{EV adoption scenario analysis}

- Based on the issues identified by our literature review and qualitative research, we sought to create a bottom-up simulation to assess how the scale of EV adoption and various charging behaviors can change load patterns in the Public Service Company of Colorado (PSCo) balancing authority area.*

- Questions:

- In a business as usual (BAU) scenario, does charging align with the existing evening peak demand?

- How does charging differ by location and charging type (home, workplace, DCFC)?

- Would a TOU rate reduce the evening peak?

- Can charging be coordinated to better align with times with a low marginal cost of energy (system lambda value)?

* In this study, "PSCo" refers to the balancing authority and "Xcel" refers to the utility. 


\section{Eight modeled scenarios}

\section{- Scale of EV adoption is based on scenarios outlined by the Colorado Energy Office (CEO 2015)}

\begin{tabular}{|c|c|c|}
\hline Number of EVS & Charging Behavior & Description \\
\hline \multirow{4}{*}{$\begin{array}{c}\text { CEO Medium } \\
2030 \text { Adoption }(302,429 \mathrm{EVs})\end{array}$} & $\begin{array}{l}100 \% \text { No Delay (all immediate on- } \\
\text { demand charging) }\end{array}$ & Business as usual \\
\hline & $50 \%$ No Delay / 50\% TOU & $\begin{array}{l}\text { Moderate utilization of existing } \\
\text { TOU rates }\end{array}$ \\
\hline & $\begin{array}{l}50 \% \text { No Delay / } \\
50 \% \text { Demand Response }\end{array}$ & $\begin{array}{l}\text { Moderate utilization of } \\
\text { controllable charging }\end{array}$ \\
\hline & $\begin{array}{l}\text { 34\% No Delay / 33\% TOU / } \\
\text { 33\% Demand Response }\end{array}$ & Split between various programs \\
\hline \multirow{4}{*}{$\begin{array}{c}\text { CEO High } \\
2030 \text { Adoption }(940,000 \mathrm{EVs})\end{array}$} & 100\% No Delay & BAU with high EV adoption \\
\hline & $50 \%$ No Delay / 50\% TOU & $\begin{array}{l}\text { High utilization of existing TOU } \\
\text { rates }\end{array}$ \\
\hline & $\begin{array}{l}50 \% \text { No Delay / } \\
50 \% \text { Demand Response }\end{array}$ & $\begin{array}{l}\text { High utilization of controllable } \\
\text { charging }\end{array}$ \\
\hline & $\begin{array}{l}\text { 34\% No Delay / 33\% TOU / } \\
\text { 33\% Demand Response }\end{array}$ & Split between various programs \\
\hline
\end{tabular}




\section{No delay / TOU scenarios: average load}

Low EV adoption, $50 \%$ utilization of existing TOU plan (average load by hour)

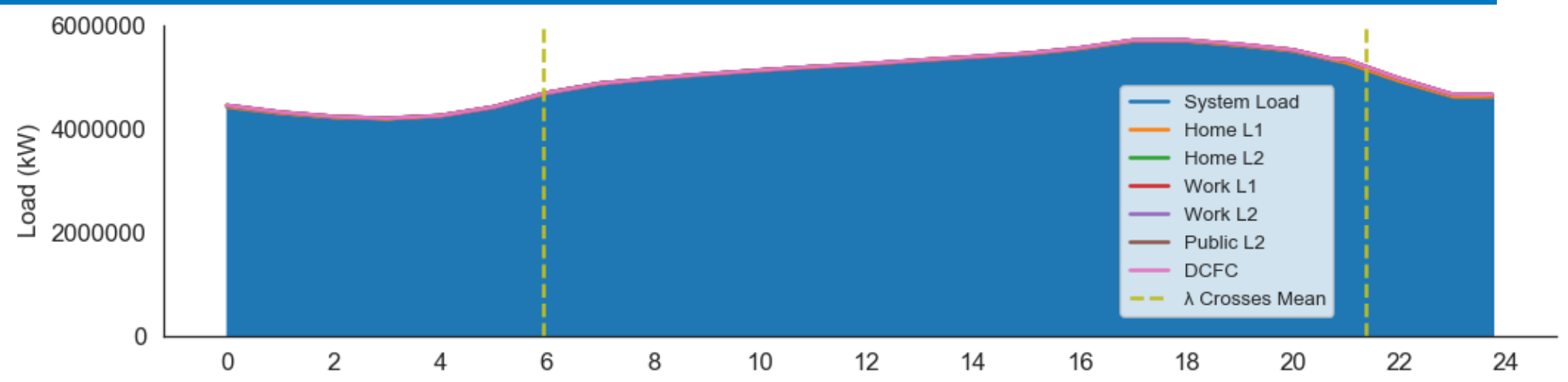

Medium EV adoption, 50\% utilization of existing TOU plan (average load by hour)

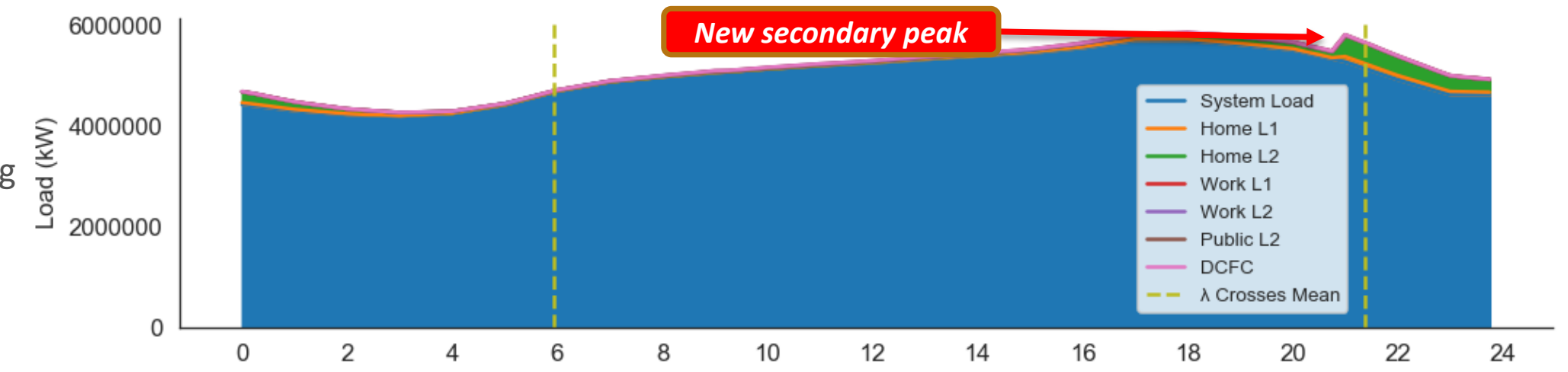

High EV adoption, $50 \%$ utilization of existing TOU plan (average load by hour)

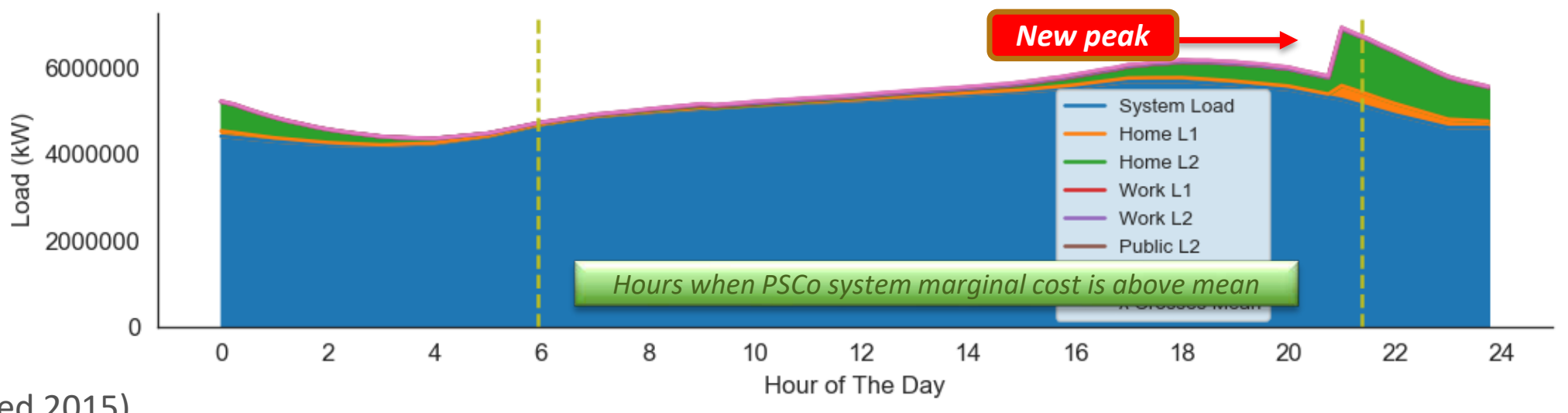

(BCS Incorporated 2015) 


\section{No delay / DR scenarios: average load}

Low EV adoption, $50 \%$ utilization of residential DR charging (average load by hour)

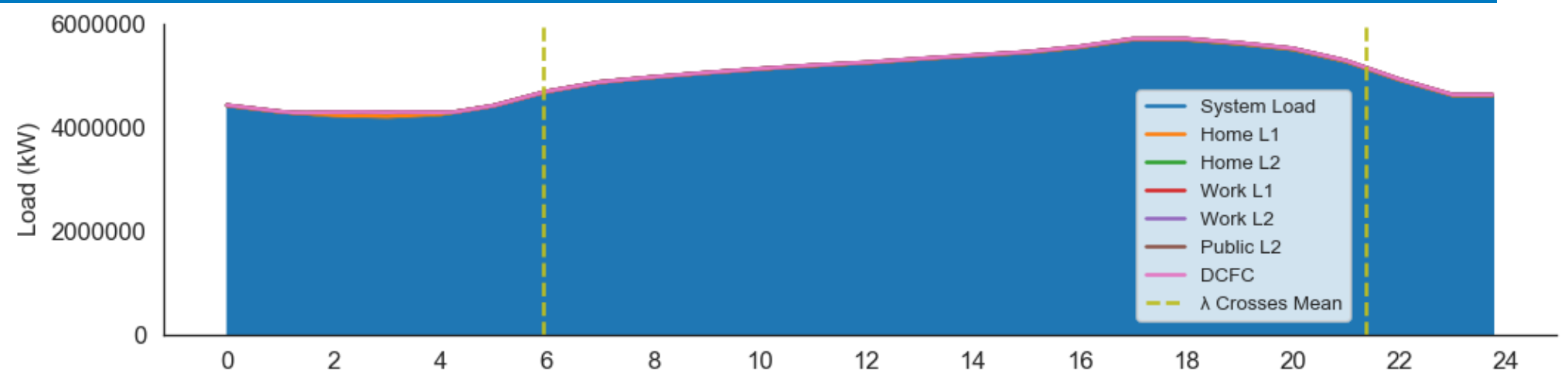

Medium EV adoption, 50\% utilization of residential DR charging (average load by hour)

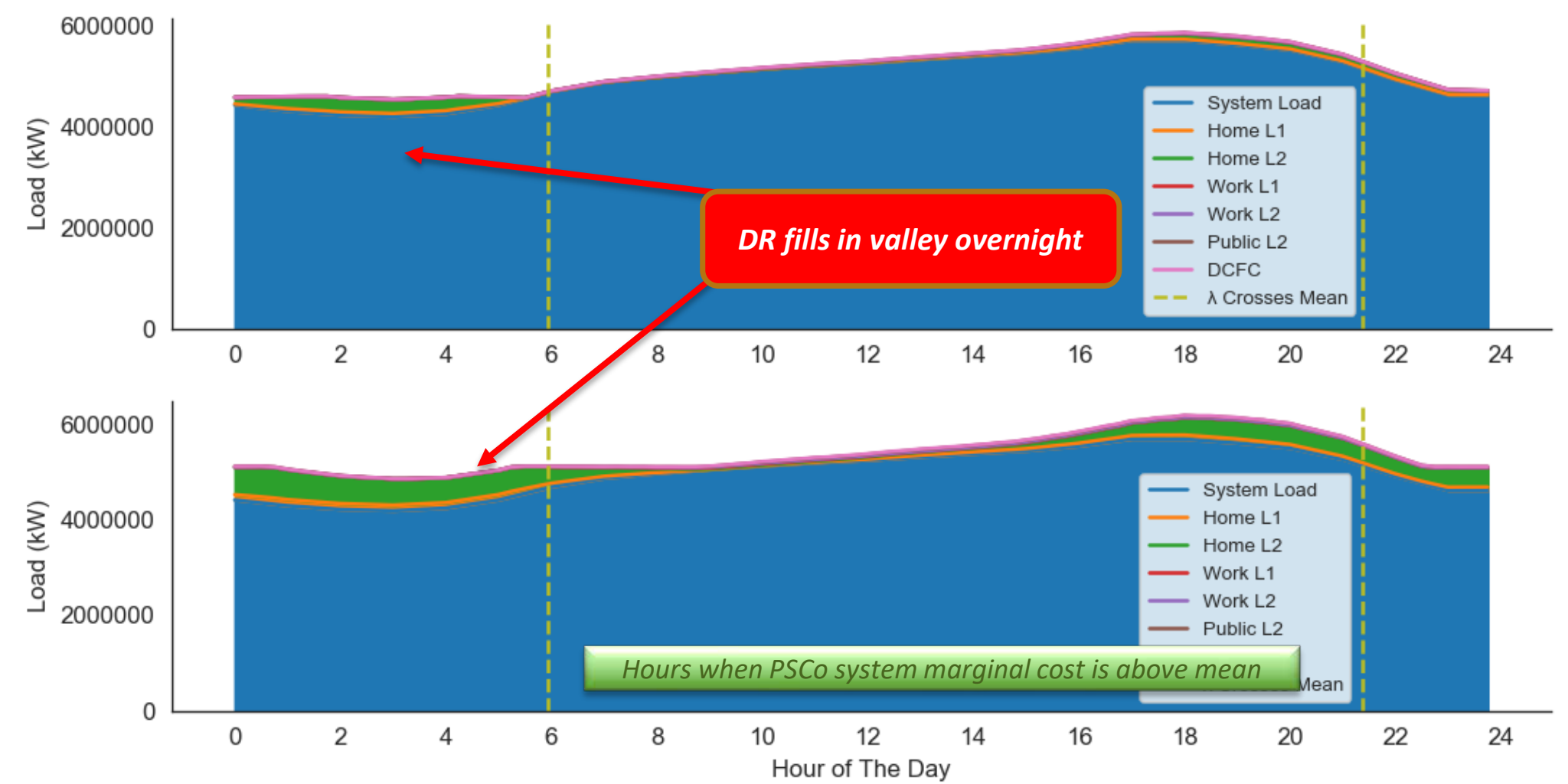




\section{Insights}

- What EV charging behaviors might systematically increase or decrease the utility's cost of service in Colorado?

- Charging during periods with low system cost

- How would load profiles change if they reflected reasonably achievable behaviors that reduced the cost of service?

- TOU rates would likely mitigate peak load growth by shifting charging load to low-cost hours

- However, the 9 p.m. TOU transition period could result in a new evening peak as well as a brief but steep demand ramp, if EV charging is not spread out using $D R$ 


\section{EV charging and integrating renewables}

- Many EV-DR studies to date have focused on California, where the system is solar-heavy.

- Integration problem: GW of net demand increase over 3 hours prior to peak

- Colorado is wind-heavy; conclusions about DR drawn from a solar-heavy system might not be applicable to Colorado

CAISO demand and net demand (demand minus renewables), January 24, 2019

$$
30,000
$$

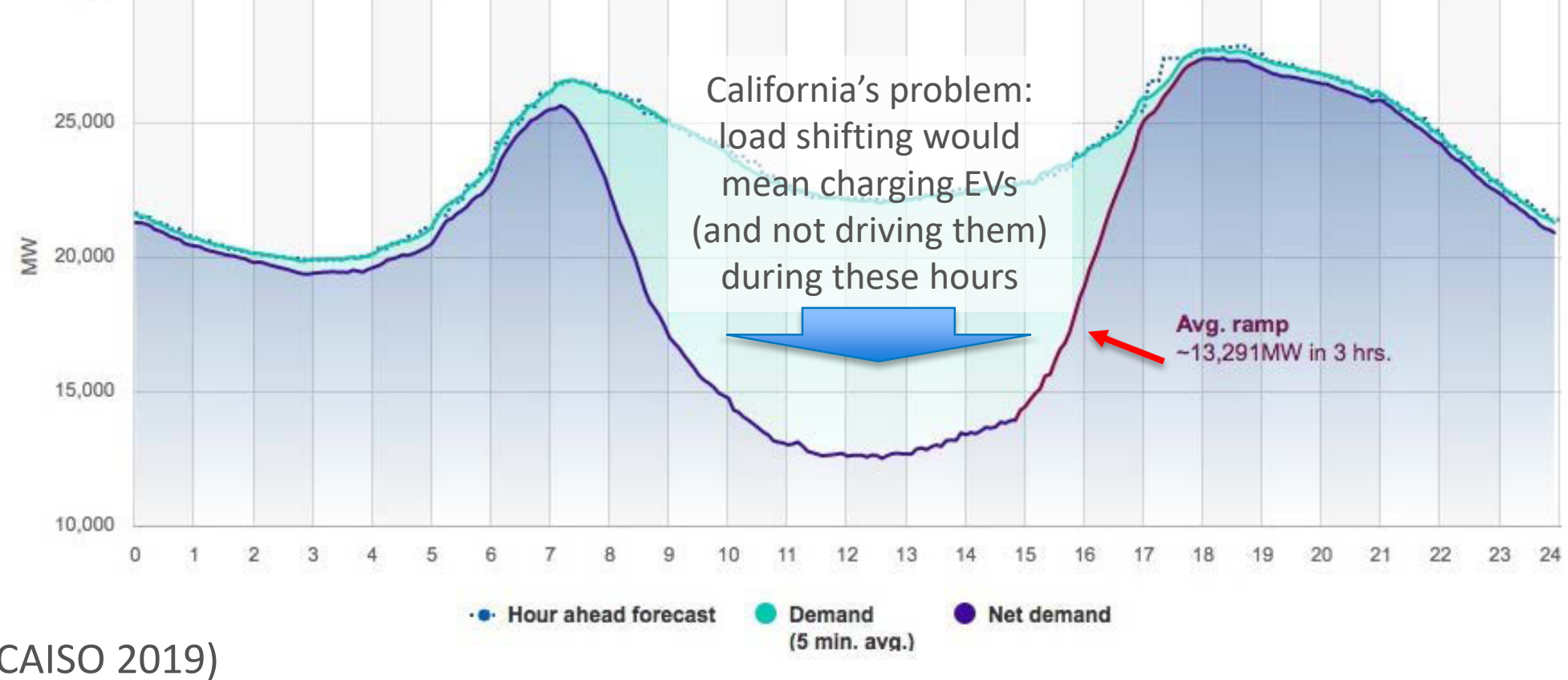




\section{Colorado's problem: Intra-hour wind variability}

\section{5-minute wind production variability at 2 sites near Rush Creek, 7 p.m. to 8 p.m., Aug. 22, 2007}

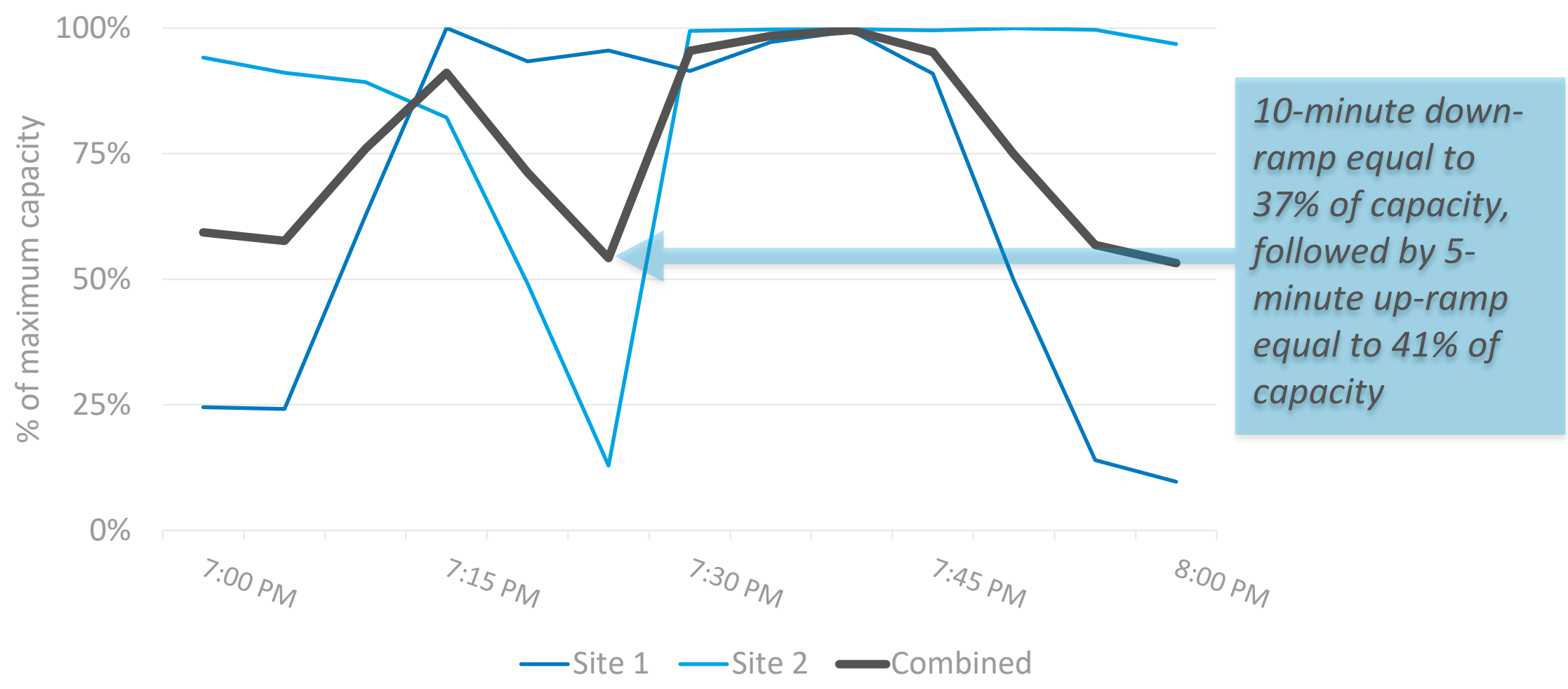

Data from NREL Wind Toolkit (Draxl et al. 2015). Site 1: 39.066589N 103.14948W. Site 2: 39.004436N 102.40137W. Annual data for 2007 was representative of 20-year average (1997-2017) 


\section{Intra-hour variability of Colorado wind}

- High ramps at two test sites tend to occur in the afternoon, early evening

- Coincident with charging patterns (see slide 10)

- Need for further study of actual output from Colorado wind plants

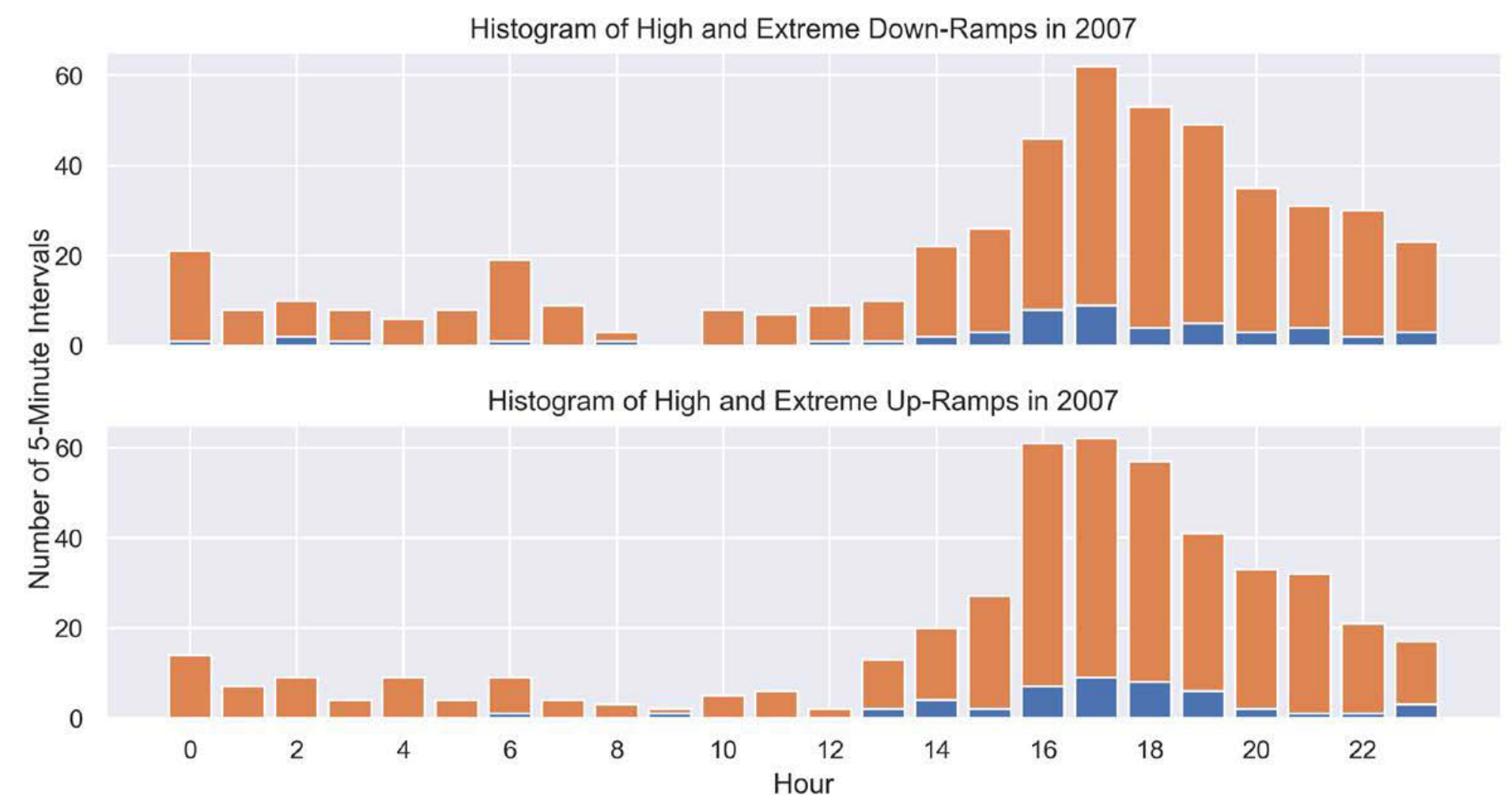

High wind ramping: $1 \%$ of 5 -minute intervals with the greatest change in wind output Extreme wind ramping: $0.1 \%$ of 5-minute intervals with the greatest change in wind output Calculated for two sites from NREL Wind Toolkit (Draxl et al. 2015) 


\section{Colorado EV Load Model: Insights}

- What EV charging behaviors might systematically increase or decrease the utility's cost of service in Colorado?

- The ability to vary charging load up or down in the evening to balance load and maintain system stability

- How would load profiles change if they reflected reasonably achievable behaviors that reduced the cost of service?

- Controlled charging, if used extensively and if EV adoption were high, might mitigate the tendency for a new peak to form under existing TOU rates

- Note: Controlled charging is similar in some ways to inverterbased power generation, which uses power system programming to respond to grid conditions that are detected 


\section{Key Insights: Managing residential EV load}

- Based on modeled results, residential charging presents the largest potential impact on system peak and the largest potential for load shifting.

- Well-designed time-of-use (TOU) rate structures can shift majority of EV charging load to times of low marginal cost of energy.

- A price differential of at least 2:1 peak to off-peak prices appears to be effective at shifting majority of load.

- TOU can be combined with demand response (DR) to further encourage load shifting. 


\section{Residential TOU rates}

- $14 \%$ of US utilities offer residential TOU rates, $48 \%$ of IOUs offer a TOU rate

- Among two-period TOU programs, 71\% have a price ratio of at least 2:1

- Price elasticity is 0.3-0.5 (Nexant, 2014)

- Opt-in TOU programs tend to have $<20 \%$ enrollment, whereas opt-out (default) TOU programs have seen $>90 \%$ participation (Whited et al., 2018)

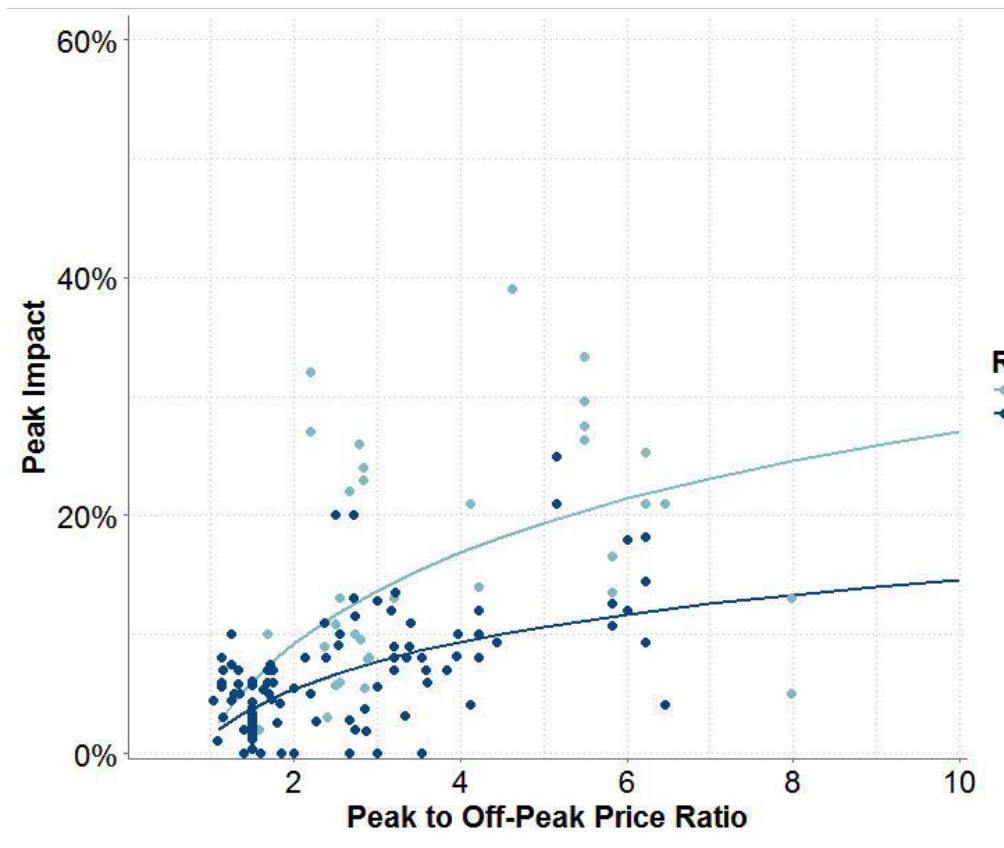

$$
\begin{aligned}
& \text { As the price ratio increases, } \\
& \text { customers shift usage in } \\
& \text { greater amounts, but at a } \\
& \text { declining rate }
\end{aligned}
$$

Chart based on database of TOU rates in recent pricing pilots, including international pilots (15 of $38 \mathrm{TOU}$ pilots in the database). (The Brattle Group 2017) 


\section{Utility TOU rates specific to EV customers}

Tariff hours and rates $(\phi / \mathrm{kWh})$

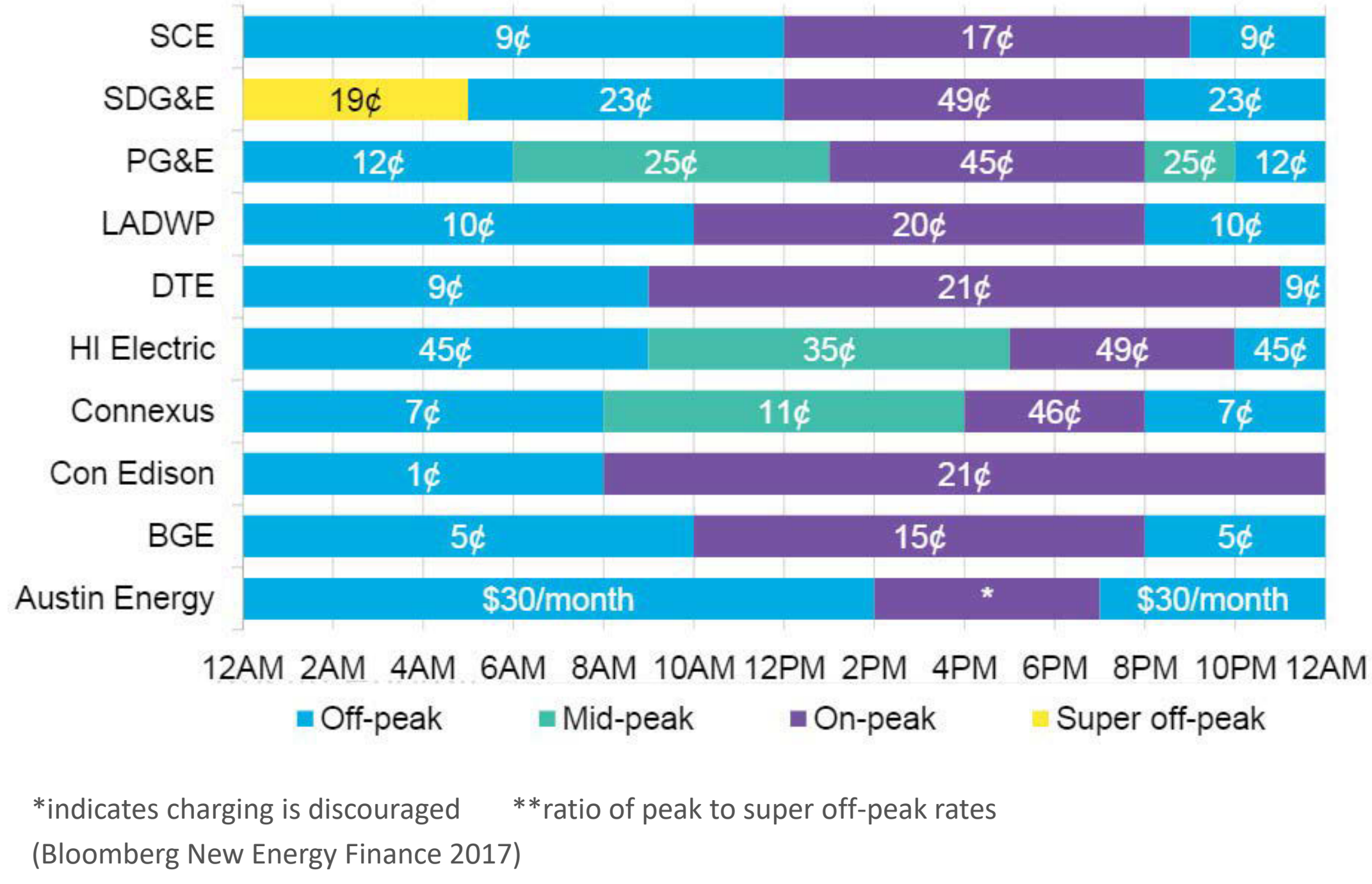

Peak to off-peak ratio 1.89: 1 2.58: $1^{* *}$

3.75: 1 2: 1 2.3: 1 1.4: 1 6.57: 1 21: 1 3: 1 


\section{Utility pilots overview}

\begin{tabular}{|c|c|c|}
\hline Utility & $\begin{array}{l}\text { Charging } \\
\text { Type }\end{array}$ & Description \\
\hline $\begin{array}{l}\text { Southern California } \\
\text { Edison (SCE) }\end{array}$ & Workplace & $\begin{array}{l}\text { Rate: TOU pricing } \\
\text { DR: Events with critical peak pricing } \\
\text { Additional Fees: space management fees }\end{array}$ \\
\hline $\begin{array}{l}\text { Pacific Gas and } \\
\text { Electric (PGE) }\end{array}$ & Residential & $\begin{array}{l}\text { Rate: TOU } \\
\text { DR: Flexible grid resource for CAISO - storage + EV }\end{array}$ \\
\hline $\begin{array}{l}\text { San Diego Gas and } \\
\text { Electric (SDG\&E) }\end{array}$ & Residential & Rate: TOU rates with multiple price ratios \\
\hline Xcel (Colorado) & Residential & $\begin{array}{l}\text { Rate: TOU (not EV-specific) } \\
\text { DR: to avoid system peak load }\end{array}$ \\
\hline $\begin{array}{l}\text { Pepco } \\
\text { (Maryland) }\end{array}$ & Residential & $\begin{array}{l}\text { Rate: TOU rate } \\
\text { DR: curtail demand by } 80 \% \text {. }\end{array}$ \\
\hline $\begin{array}{l}\text { Toronto Hydro } \\
\text { (Toronto, Canada) }\end{array}$ & Residential & DR: with automated opt-out \\
\hline $\begin{array}{l}\text { Eversource } \\
\text { (Massachusetts) }\end{array}$ & Residential & $\begin{array}{l}\text { Managed charging, through speed of charging. } \\
\text { Shaping load profile }\end{array}$ \\
\hline
\end{tabular}




\section{Toronto Hydro EV pilot}

- Aim: Automated managed charging during demand response events

- Duration: 15 months

- Participants: 30 plug-in EV owners

- Technology: FleetCarma smart charging system, with 1) charge management controller, 2) vehicle logger, 3) web portal for individual smart charging preferences, 4) control pathway to implement charge curtailment

- Opt-out: Operated through web portal. Customers were enrolled in demand response events, unless:

- the current vehicle state-of-charge is less than the state-of-charge auto opt-out setting

- manual opt-out button has been hit in the last 24 hours

- charge is needed to ensure full battery charge within time setting

- Results: Successful in reducing demand and providing DR flexibility. However, DR participation was sensitive to how the customer set the stateof-charge auto opt-out. 


\section{Eversource EV pilot}

- Aim: Control demand by targeting the speed of EV charging.

- Duration: ongoing

- Participants: Up to 105 residential customers in Massachusetts, incentivized with subsidy for smart chargers.

- Opt-out: Dependent on the research group

1. Control group, only personal rate management, no utility management

2. \$10 monthly bill credit for allowing utility direct management, but cannot have more than four overrides a month to receive the credit.

3. \$10 monthly bill credit for allowing utility direct management, with unlimited overrides allowed.

4. Utility management only reduces the charging to Level 1 charging.

- Preliminary Results: Only 5\% of charging sessions used overrides. Customer adoption of smart chargers "very sensitive to capital cost of chargers, indicating the importance of the rebate." 


\section{EV Program Design Considerations}

EV specific rate design should consider the following elements:

- Pairing residential TOU with DR capability

- Aligning time periods of TOU rate blocks with EV load

- TOU programs targeting 2-6pm did not have sufficient residential load to shift.

- Potential Program Costs

- Metering

- Cost of a second meter

- Cost of master metering/submetering (savings of $\$ 2,000$ to $\$ 10,000$ compared to adding second meter)

- Electric Vehicle Supply Equipment (EVSE)

- Incremental cost of EVSE with DR capability

- Data/communication services

- Participation structure

- Default bias (opt-in, opt-out)

- Communication medium (text, email, web portal, etc.) 


\section{Other utility mechanisms for shaping EV load}

Beyond the prior examples, utilities and regulators have multiple rate and program tools to impact customer charging behavior:

- Electricity rates

- Energy charge, demand charge, fixed charge

- TOU

- DR programs

- Rebates on equipment or professional services

- Rebates for preferred chargers

- Rebates for installation of preferred chargers

- Installment plans for infrastructure cost

- Customer pays installments to the utility for ownership of equipment 


\section{Key Insights: TOU + DR + Connected EVSE}

- TOU can be a powerful tool to manage residential EV load, but has the potential to create new or secondary peaks.

- Pairing TOU with DR or direct utility control of EV charging can allow utilities to unlock benefits of managed charging.

- Deploying EV charging infrastructure with the capability to respond to system needs presents utilities an opportunity to prepare for and manage expected EV load. 


\section{Charging technologies}

- Level 1

- Typically 1.4kW / 12Amp / 120V

- SAE J1772 connector

- Used in home and workplace charging

- Level 2

- Typically 7.2kW / $30 \mathrm{Amp} / 240 \mathrm{~V}$

- Up to $19.2 \mathrm{~kW} / 80 \mathrm{Amp}$

- SAE J1772 connector

- Used in home, workplace and public charging

- DCFC

- Ranges 36kW / 75Amp / 480V (3-phase AC input) to $350 \mathrm{~kW}$. Typically $50 \mathrm{~kW}$.

- SAE CCS, CHAdeMO, Tesla Supercharger (120kW)

- Used in public, workplace and fleet charging

- Most LDVs currently cannot accept a charge $>240 \mathrm{~kW}$, although buses may go up to $350 \mathrm{~kW}$. 


\section{Networked vs. non-networked chargers}
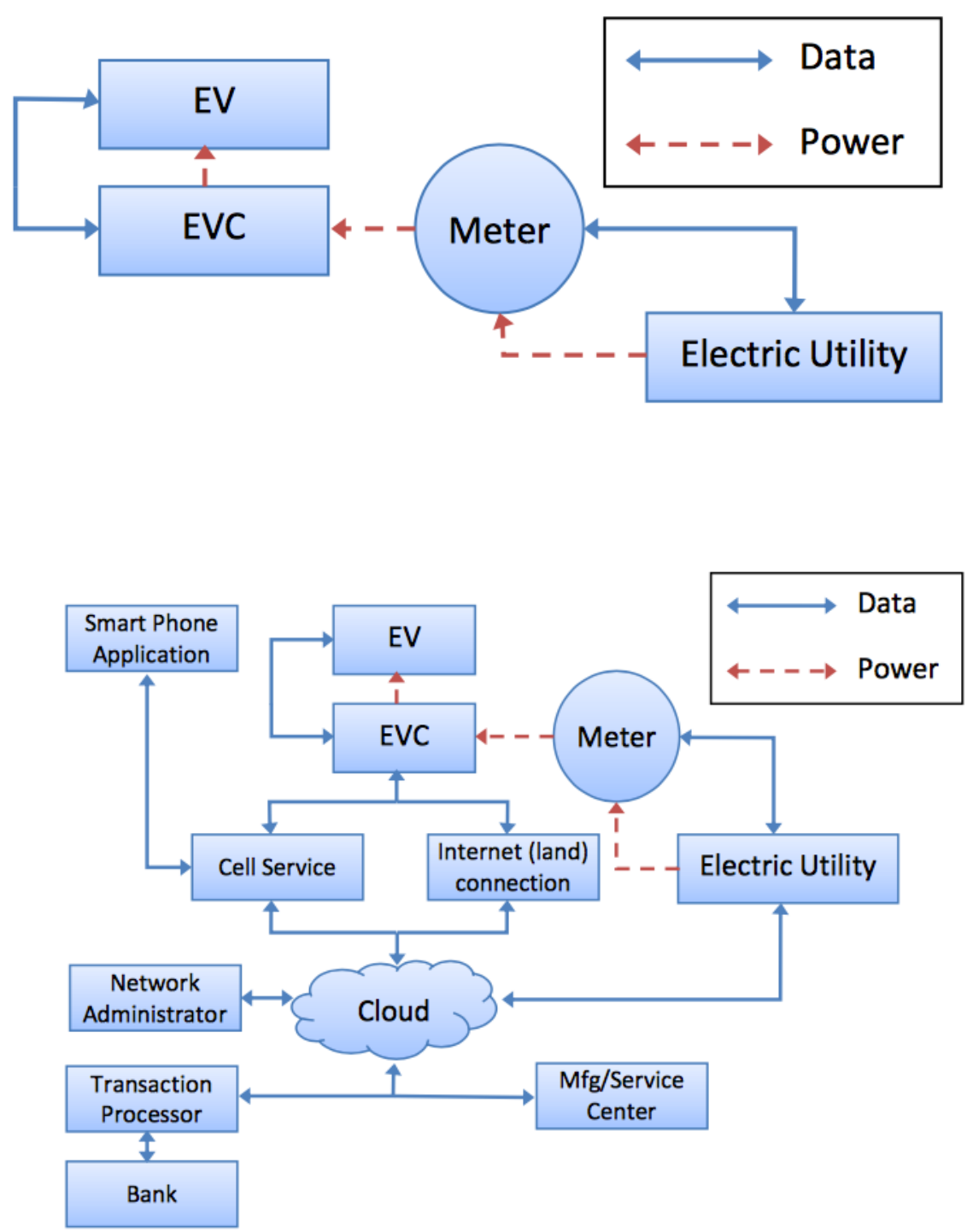

- Non-networked chargers communicate and provide charge to the electric vehicles that are directly connected. Can be programmed.

- Networked chargers allow vehicles, charging stations and/or the customer to adjust charging profile based on price or load signals from the utility. Networking provides utilities or aggregators with data to optimize charging across multiple stations. 


\section{EVSE with control capabilities}

- Approximately one-third of EV charger manufacturers offer charging stations with utility control capabilities (Smart Electric Power Alliance 2017)

- Includes Level 1, Level 2 and DCFC

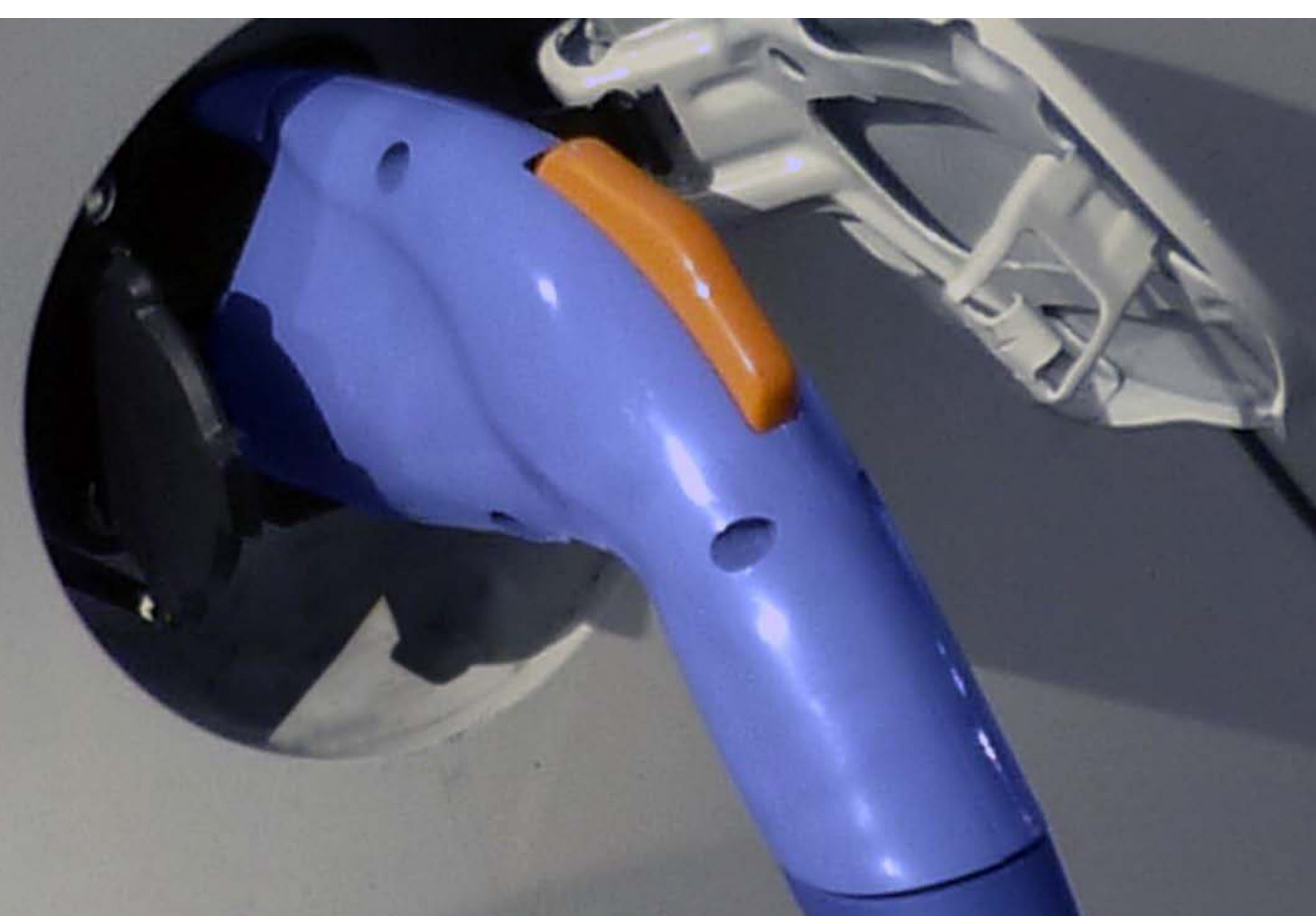




\section{EVSE with control capabilities}

- Charging station communication protocols

- Smart chargers receive load or price signals from the utility and communicate with the vehicle to manage the charging voltage or current. Common protocols include:

- Open Automated Demand Response (OpenADR) 2.0

- Smart Energy Profile (SEP) 1.x and 2.0

- Open Charge Point Protocol (OCPP) 1.5, 1.6 and 2.0

- Open Smart Charging Protocol (OCSP)

- Attachments

- After-market products such as FleetCarma SmartCharge Manager (vehicle attachment) and GreenFlux DUO and PLUS (charger attachments) can also provide EV load management.

- Attachments may have limited number of protocols they support, but can work across EVSE manufacturers. 


\section{Networked EVSE costs}

- Incremental charger cost example:

- Southern California Edison's Charge Ready Home Installation Rebate Program includes 62 approved Level 1 and 2 models with various capabilities to program and manage charging

- Price differential between networked and non-networked Level 2 chargers in SCE's program: $\sim \$ 1,250$ per port (El Paso Electric 2018) 


\section{Considerations for EV charger deployment}

- Programs to incentivize deployment of EVSE with control capability should consider:

- Capital costs

- Ongoing program management needs

- Interoperability of communication protocols

- Avoiding path dependence

- Deploying EVSE appropriate to targeted customer segment 
6. Public Direct-Current Fast

6. Public Direct-C
Charging (DCFC)

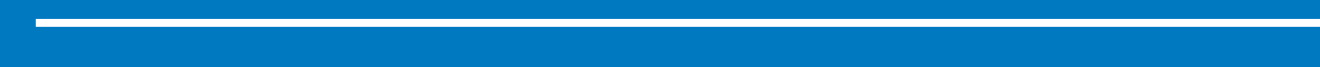




\section{Key insights: Public DCFC charging}

- Programs like the CEO DC Fast Charging Corridor buildout could result in Colorado having a sufficient number of charging ports for the anticipated number of EVs in 2020.

- This analysis suggests that demand charges in the applicable electricity rates could significantly affect the pace and location of private-sector buildout of DCFCs.

- The locations of existing EV and hybrid car adoption can be used to inform future charger buildouts. 


\section{EV adoption trends in the metro Denver region}

- Hybrid vehicles are a similar but mature technology, so studying the areas with high levels of hybrid adoption can help forecast the areas with expected EV adoption.

- Predicting where EVs will be adopted can help plan the build-out of public chargers.

- Zip codes in South-East Denver and the suburbs of Boulder have a large margin between the number of EVs and number of hybrids.

For an interactive version of this map, see https://skoeb.github.io/CO-EV-Rate-Map/

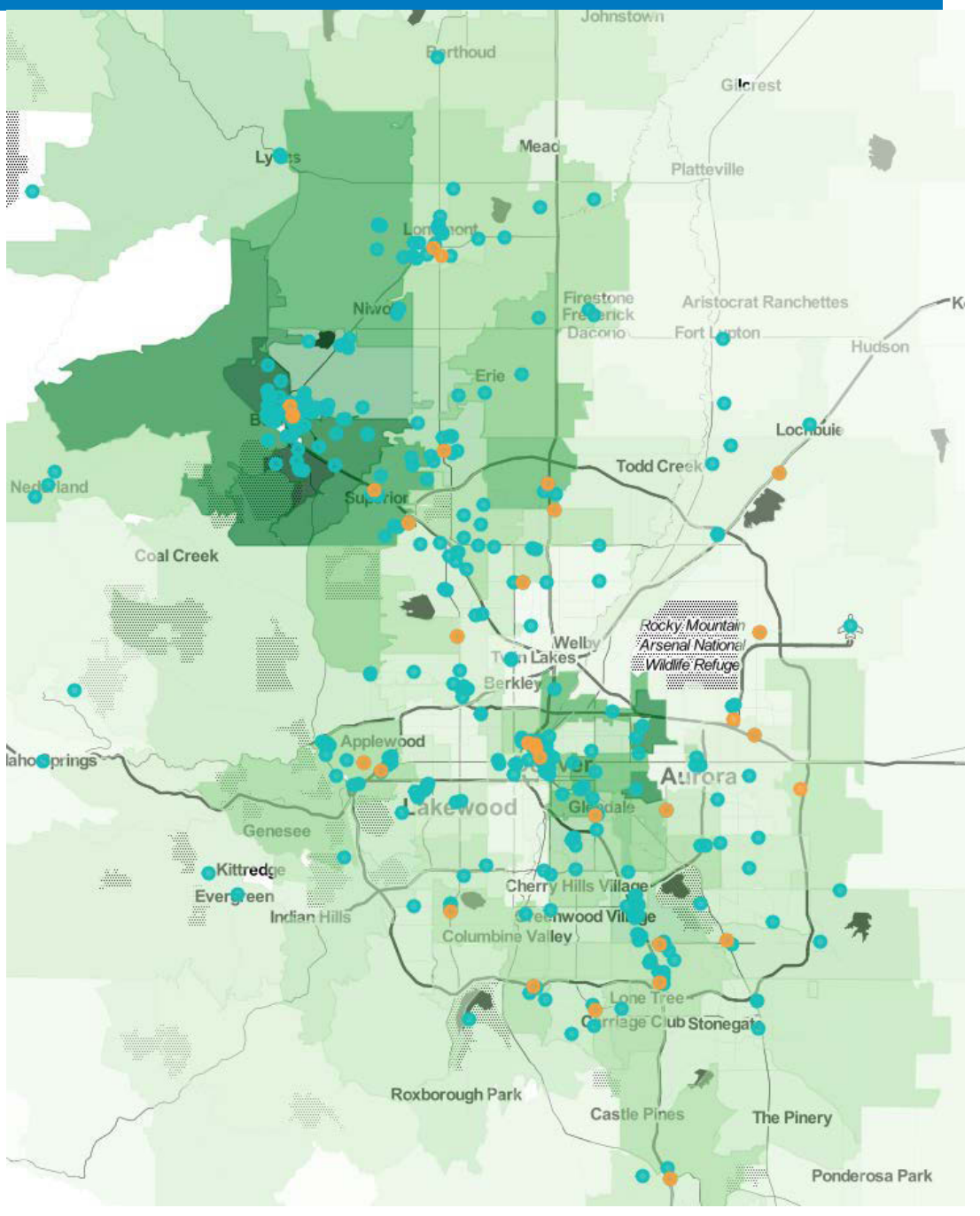

Map created by NREL using Polk Vehicle Registration data. Darker-shaded zip code areas indicate higher percentages of hybrid vehicles. Orange dots indicate public DCFC charging stations; blue dots indicate public Level 2 charging stations. 


\section{Public EV charger buildout}

- 1,529 Level 2 and 219 DCFC public charging ports in Colorado (as of February 1, 2019)

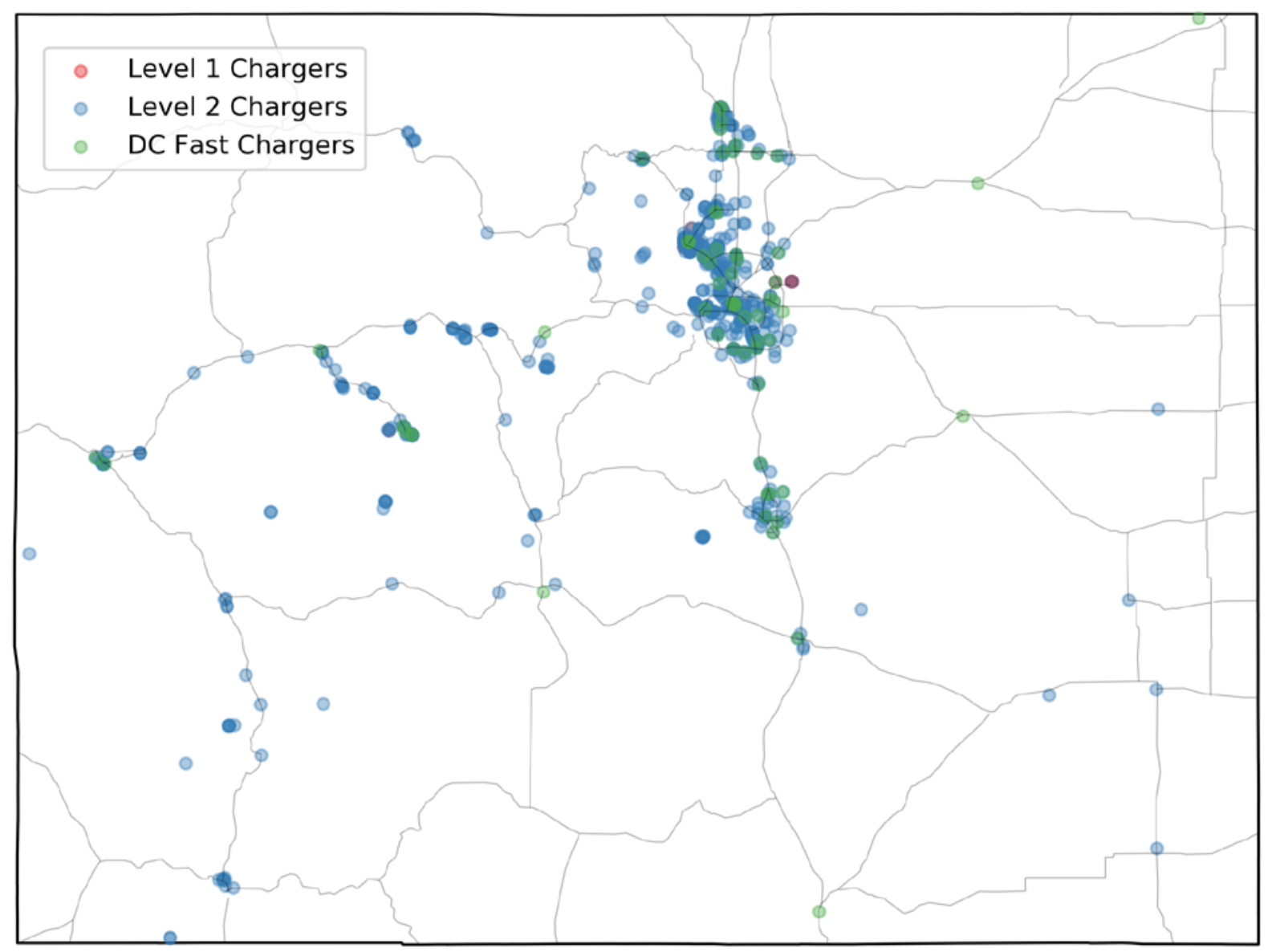

(Alternative Fuels Data Center 2019) 


\section{Public EV charger deployment}

\begin{tabular}{ll|l|}
\multirow{2}{*}{} & \multicolumn{2}{c|}{ Projected Public Charger Demand in CO } \\
\cline { 2 - 3 } & \multicolumn{1}{c|}{$\mathbf{2 0 2 0}$} & \multicolumn{1}{c|}{$\mathbf{2 0 3 0}$} \\
\hline Low EV Adoption & 719 Level 2 ports & 925 Level 2 ports \\
Scenario & 80 DCFC ports & 103 DCFC ports \\
\hline $\begin{array}{l}\text { Medium EV Adoption } \\
\text { Scenario }\end{array}$ & $\mathbf{1 , 9 4 4}$ Level 2 ports & $\mathbf{7 , 3 5 3}$ Level 2 ports \\
\hline $\begin{array}{l}\text { High EV Adoption } \\
\text { Scenario }\end{array}$ & 4,860 Level 2 ports & 22,775 Level 2 ports \\
\hline
\end{tabular}

(BCS Incorporated 2015; Wood and Rames 2017)

- Number of chargers needed to support EV adoption scenarios, which may be lower than the number of chargers needed to alleviate "range anxiety."

- CEO EV Fast Charging Corridor program will add 33 DCFC stations with 94 expected ports, along with stations funded by Charge Ahead Colorado and Electrify America. 


\section{DCFC load factor and demand charges}

- Usage of DCFC stations is currently relatively low, especially in early stages of market development.

- EEl estimates average load factor of $2 \%$ for DCFC stations

- "Highly utilized" DCFC stations in California to have 15-20\% load factor, though a few have $>50 \%$ load factor

- At low utilization with standard rate schedules, demand charges tend to dominate monthly bills for DCFC stations.

- Xcel's Secondary General Low-Load Factor rate results in lower bills up to approximately $11 \%$ load factor compared to the Secondary General rate.

- Adding DCFC to an existing large commercial account may reduce the need for transformer upgrades, the total installation costs, and the impact of demand charges. 


\section{Alternative rates to manage DCFC load}

- If desired, alternative rate structures can be designed to decrease demand charges.

- Energy-only rate with monthly energy consumption thresholds $(2,000$; $3,000 ; 5,000 ; 8,000 \mathrm{kWh})$

- PSEG Long Island ( $<2,000 \mathrm{kWh})$, Village of Akron $(<7,500 \mathrm{kWh})$

- Hybrid rates with peak power threshold classes $(50,60,75,100$, or 200 $\mathrm{kW}$ ) and monthly energy consumption threshold

- Rate limiter, maximum allowable rate that customers can be charged

- Developed in California for electric buses 


\section{Rate structures that support PV or storage}

- NREL analyzed which CO rate structures allow addition of solar PV or battery storage to be economic (Muratori et al., forthcoming)

- Rates with the following characteristics support addition of PV or batteries:

- Demand charges: $>\$ 10 / \mathrm{kW}$ (batteries improved economics)

- Time-of-use: > 3.5:1

- Energy costs: > 0.128/kWh (PV improved economics) 


\begin{tabular}{|c|c|c|c|}
\hline Utility & Demand charge & Energy charge & PV/Battery \\
\hline \multirow{3}{*}{$\begin{array}{l}\text { Sangre de } \\
\text { Cristo Electric } \\
\text { Association }\end{array}$} & $\begin{array}{l}\text { Peak: } \$ 30.1 / \mathrm{kW} \\
\text { Off-Peak: } \$ 4.2 / \mathrm{kW}\end{array}$ & $\begin{array}{l}\text { Peak: } \$ 0.0483 / \mathrm{kWh} \\
\text { Off-Peak: } \$ 0.02835 / \mathrm{kWh}\end{array}$ & $\mathrm{B}: 21 \mathrm{~kW}$ \\
\hline & -- & $\begin{array}{l}\text { Peak: } \$ 0.53 / k W h ; \text { Off-Peak: } 0.15013 / k W h \\
\text { Super off-peak: } \$ 0.04305 / k W h \quad 12.3: 3.5: 1\end{array}$ & B: $15 \mathrm{~kW}$ \\
\hline & $\$ 30.1 / \mathrm{kW}$ & $\$ 0.06173 / \mathrm{kWh}$ & $\mathrm{B}: 19 \mathrm{~kW}$ \\
\hline $\begin{array}{l}\text { San Luis Valley } \\
\text { REC }\end{array}$ & -- & $\begin{array}{l}\text { Peak: } \$ 0.344 / k W h \\
\text { Off-peak: } \$ 0.055 / k W h\end{array}$ & $\begin{array}{l}\text { B: } 12 \mathrm{~kW} \\
\text { PV: } 11 \mathrm{~kW}\end{array}$ \\
\hline Black Hills & $\$ 22.8 / \mathrm{kW}$ & $\$ 0.00573 / \mathrm{kWh}$ adj. $\$ 0.04324698 / \mathrm{kWh}$ & $\mathrm{B}: 14 \mathrm{~kW}$ \\
\hline \multirow{2}{*}{$\begin{array}{l}\text { Intermountain } \\
\text { Rural Electric } \\
\text { Association }\end{array}$} & $\$ 17.25 / \mathrm{kW}$ & $\$ 0.05344 /$ kWh (buy/sell rate) & $\mathrm{B}: 7 \mathrm{~kW}$ \\
\hline & $\begin{array}{l}\text { Peak: } \$ 10.03 / \mathrm{kW} \\
\text { Off-peak: } \$ 7.2 / \mathrm{kW}\end{array}$ & $\$ 0.05344 / \mathrm{kWh}$ & $\mathrm{B}: 7 \mathrm{~kW}$ \\
\hline Xcel & $\begin{array}{l}\text { Peak: } \$ 15.8 / k W \text { (June-Sept) } \\
\text { Off-peak: } \$ 12.8 / \text { kW (Oct-May) }\end{array}$ & $\$ 0.00473 / \mathrm{kWh}$ with $\$ 0.02683 / \mathrm{kWh}$ & $\mathrm{B}: 7 \mathrm{~kW}$ \\
\hline United Power & $\$ 16 / k W$ & $\$ 0.0575 / \mathrm{kWh}$ & $\mathrm{B}: 5 \mathrm{~kW}$ \\
\hline \multirow{3}{*}{$\begin{array}{l}\text { Springfield } \\
\text { Municipal } \\
\text { Utilities }\end{array}$} & $\$ 14.54 / \mathrm{kW}$ & $\$ 0.0911 / \mathrm{kWh}$, with $0.005 / \mathrm{kWh}$ adjustment & $\begin{array}{l}\text { B: } 5 \mathrm{~kW} \\
\text { PV: } 4 \mathrm{~kW}\end{array}$ \\
\hline & -- & $\$ 0.1455$, with $0.005 / \mathrm{kWh}$ adjustment & PV: $4.55 \mathrm{~kW}$ \\
\hline & -- & $\$ 0.1374 / \mathrm{kWh}$, with $0.005 / \mathrm{kWh}$ adjustment & PV: $2.11 \mathrm{~kW}$ \\
\hline San Luis Valley & -- & $\$ 0.128 / \mathrm{kWh}$ & PV: $2.80 \mathrm{~kW}$ \\
\hline $\begin{array}{l}\text { La Plata } \\
\text { Electric } \\
\text { Association }\end{array}$ & $\$ 14.2 / \mathrm{kW}$ & $\$ 0.061 / \mathrm{kWh}$, buy/sell & B: $5.06 \mathrm{~kW}$ \\
\hline
\end{tabular}


7. Fleet Charging

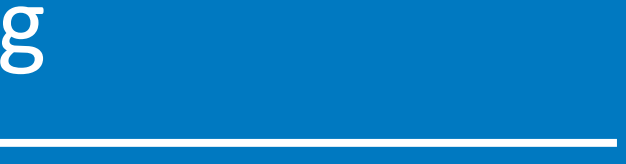

7. Fleet Charging
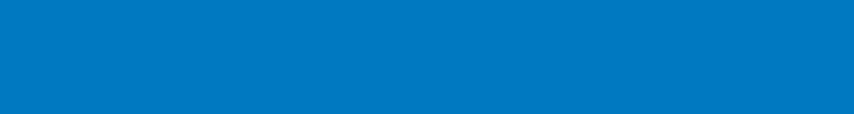


\section{Commercial fleets}

Based on limited field test data and economic modelling (variable costs, vehicle costs):

- For long distance routes, degradation costs, rather than energy costs, are limiting factor.

- Fleets using short routes with more flexible charging (i.e. within-city delivery) will be more responsive to utility rates/grid needs.

- Considering DC fast charging costs, including accelerated battery degradation and possible demand charges, DCFC infrastructure is likely not cost-effective as sole charging resource.

- Frequency-response resource may not be economical.

- ERCOT/Frito Lay Pilot: 12 Smith Electric trucks tested use of EV charging as frequency response resource (within 1 second) of $100 \mathrm{~kW}$. Small load, pilot costs, and low prices made it uneconomical. 


\section{Fast charging network for electrified ride-hailing services}

- Results: Modeling a hypothetical ride-hailing fleet of 3,726 PEVs in Columbus, Ohio, using EVIPRO identified the need for 12 DCFC stations across the city.

- Operation costs dominate the total costs. Modeling suggests DCFC station siting should prioritize locations with high utilization rather than minimal installation costs.

- DC Fast Charger Total Cost $=$ capital cost $(\$ 40,000)$ per plug + installation costs + operating costs (electricity and maintenance)

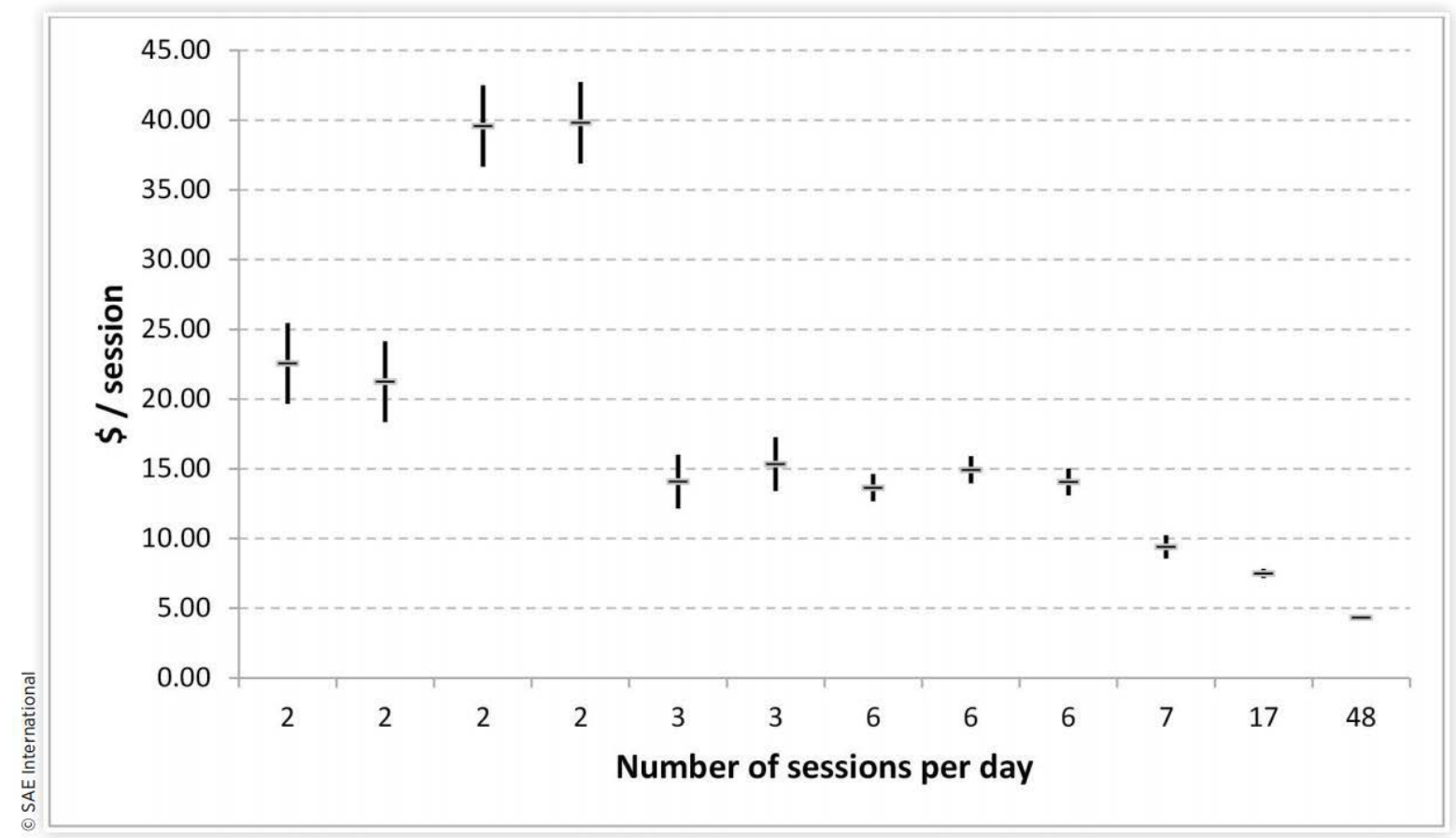

Total cost of charging infrastructure per site, assuming 10-year amortization period 


\section{Battery electric bus fleets charging}

1. Plug-in charging (Level 1 or $\mathbf{2}$ )

- Use: overnight charging with buses with large battery packs and higher range (1-8 hours).

- Consideration: managed charging to avoid a new system peak when the buses are plugged in.

2. Overhead conductive charging (DC Fast Charging)

- Use: on-route or layover charging, using fast charging at 175-450 kW power for a period (5-20 minutes). This charging is used with buses with smaller, lighter battery packs.

- Consideration: high energy demand, with limited flexibility for shifting their demand. The Foothills Transit Agency, which uses two overhead conductive chargers, has used software control to manage their demand to stay within their rate tier bounds.

3. Wireless inductive charging (DC Fast Charging)

- Use: smoother on-route charging, as buses can be charged during routine stops (i.e. transfer), with similar charging patterns as overhead conductive charging. 


\section{EV bus charging case study}

- NREL study explored cost of charging six EV buses purchased by the City of Missoula, Montana

- Two charging locations compared:

- Charging at existing bus depot

- Charging at university campus

- Assumes no change in electricity rates

Methodology Notes:

- Both cases assume each bus charges at $60 \mathrm{~kW}$ for 5 hours (from $11 \mathrm{pm}-4 \mathrm{am}$ )

- Simulations were conducted using NREL's REopt Model https://reopt.nrel.gov/

- Assumes depot load shape is equivalent to the DOE's commercial reference building load profile for a warehouse in climate zone 6B, scaled to REopt's actual annual energy consumption of 188,081 kWh from May 2017- April 2018

- Uses actual 15-minute interval data for the university campus (down-sampled to hourly data) 


\section{NorthWestern Energy electricity rates}

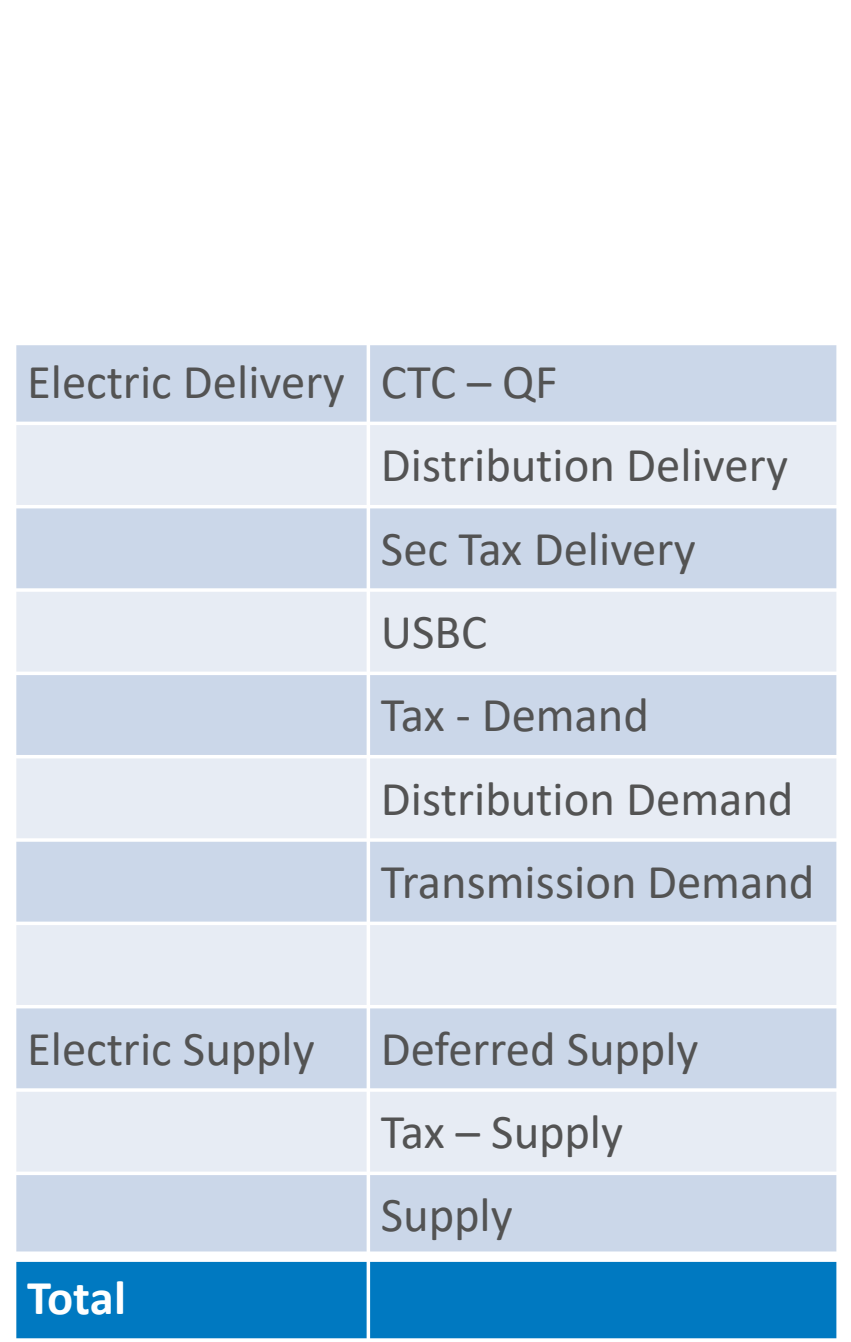

\begin{tabular}{|r|r|r|}
\multicolumn{2}{c}{$\begin{array}{c}\text { Bus depot } \\
\text { General Service - }\end{array}$} \\
Secondary Demand Rate \\
\hline $\mathbf{\$} / \mathbf{k W h}$ & $\mathbf{\$} / \mathbf{k W}$ & $\mathbf{\$} /$ month \\
\hline 0.0032410 & & \\
\hline 0.0039240 & & \\
\hline 0.0015090 & \\
\hline 0.0011430 & & \\
\hline & 2.4852570 & \\
\hline & 4.9478300 & \\
\hline & 2.4272180 & \\
\hline & & \\
\hline 0.0018050 & & \\
\hline 0.0043050 & & \\
\hline 0.0627340 & & \\
\hline $\mathbf{0 . 0 7 8 6 6 1}$ & $\mathbf{9 . 8 6 0 3 0 5}$ & $\mathbf{7 . 3 5}$ \\
\hline
\end{tabular}

\begin{tabular}{|c|c|c|}
\hline \multicolumn{3}{|c|}{$\begin{array}{l}\text { University Campus } \\
\text { E191 General Service - } \\
\text { Primary Demand Rate }\end{array}$} \\
\hline$\$ / \mathbf{k W h}$ & $\$ / \mathrm{kW}$ & $\$ /$ month \\
\hline 0.0031520 & & \\
\hline 0.0056750 & & \\
\hline 0.0020470 & & \\
\hline \multirow[t]{5}{*}{0.0009000} & & \\
\hline & 2.2097500 & \\
\hline & 3.2394250 & \\
\hline & 2.9501400 & \\
\hline & & 19.85 \\
\hline 0.0017560 & & \\
\hline 0.0037620 & & \\
\hline 0.0587210 & & \\
\hline 0.076013 & 8.399315 & 19.85 \\
\hline
\end{tabular}

Notes:

- Fixed ( $\$ /$ month) costs not included in the analysis as these cannot be offset.

- Demand charges are billed based on highest monthly peak, regardless of time of day. 


\section{Bus depot $\&$ bus charging loads}

- Simulated bus charging load is large relative to existing bus depot load

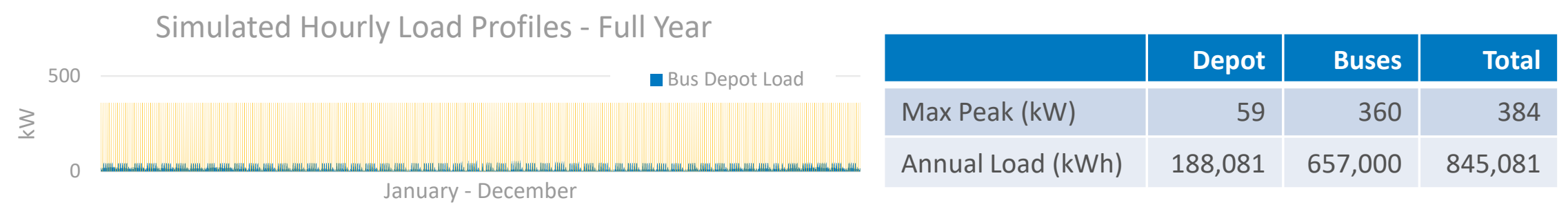

Simulated Hourly Load Profiles - 1 Week

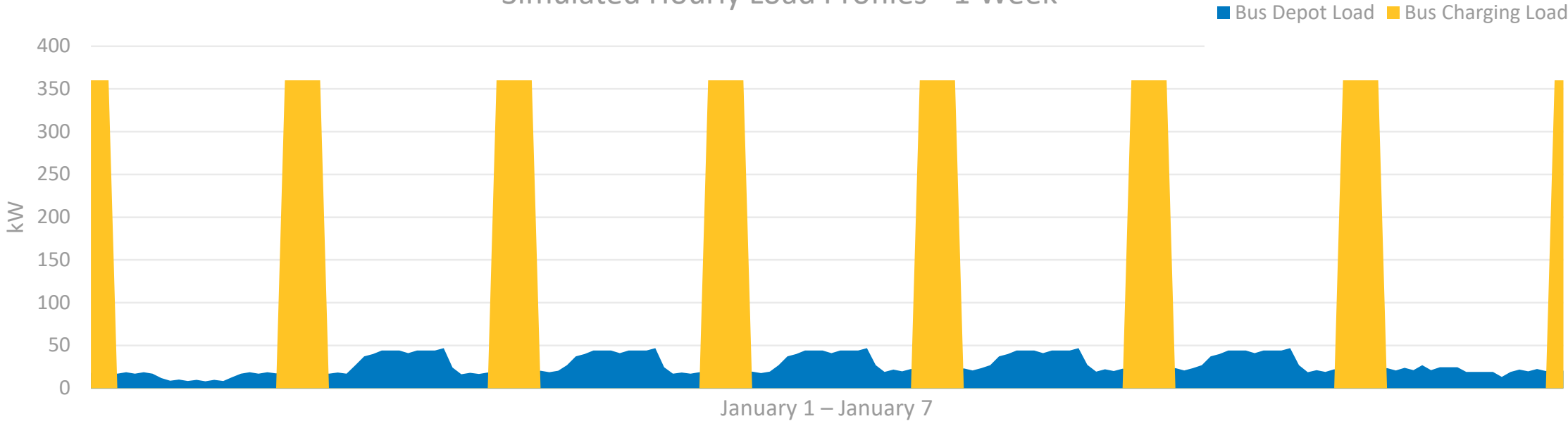




\section{University \& bus charging loads}

- The load from charging the EV buses is very small relative to university load

- The peaks of the EV buses are out of alignment with the peaks of the university

Load Profile (downsampled to hourly)

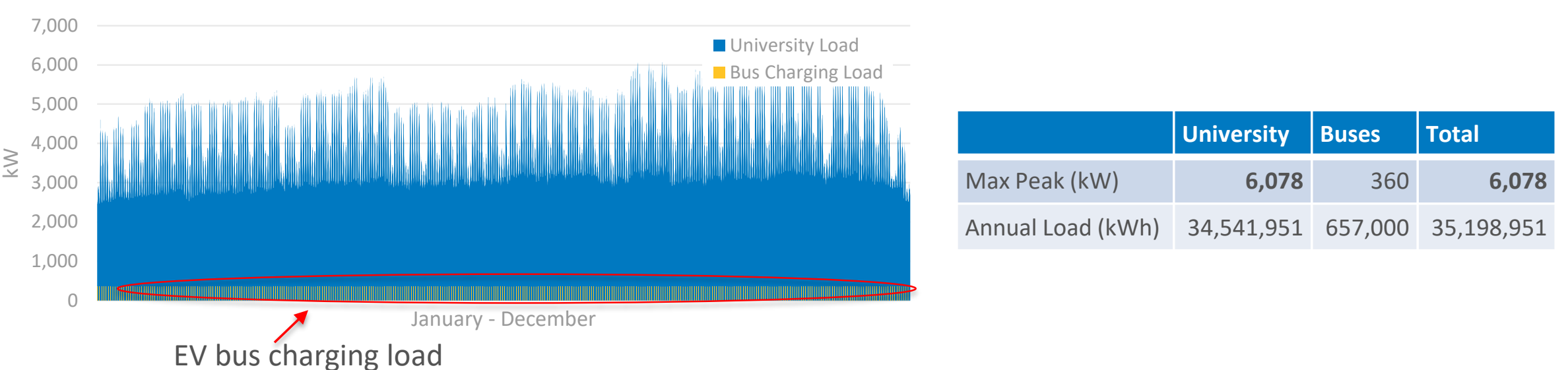

Load Profile (downsampled to hourly)

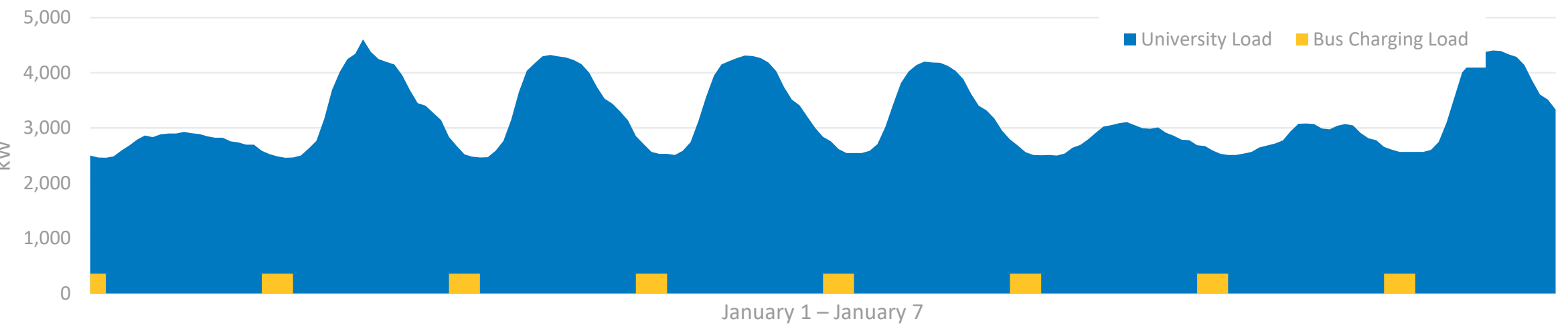




\section{Cost of electricity}

\begin{tabular}{|c|c|c|c|c|c|c|}
\hline & $\begin{array}{l}\text { Bus } \\
\text { Depot }\end{array}$ & $\begin{array}{c}\text { Bus Depot + } \\
\text { Elec Buses }\end{array}$ & $\begin{array}{c}\text { Incremental } \\
\text { Cost } \\
\text { Buses }\end{array}$ & University & $\begin{array}{c}\text { University + } \\
\text { Elec Bus }\end{array}$ & $\begin{array}{c}\text { Incremental } \\
\text { Cost } \\
\text { Buses }\end{array}$ \\
\hline Purchased Utility Electricity (kWh/yr) & 188,081 & 845,081 & 657,000 & $34,541,951$ & $35,198,951$ & 657,000 \\
\hline Year 1 Utility Electric Costs (Energy \$) & $\$ 14,801$ & $\$ 66,507$ & $\$ 51,706$ & $\$ 2,625,187$ & $\$ 2,675,203$ & $\$ 50,016$ \\
\hline Year 1 Utility Electric Costs (Demand \$) & $\$ 5,757$ & $\$ 44,626$ & $\$ 38,869$ & $\$ 569,120$ & $\$ 569,120$ & $\$ 0$ \\
\hline Year 1 Total Utility Cost (\$) & $\$ 20,558$ & $\$ 111,133$ & $\$ 90,575$ & $\$ 3,194,290$ & $\$ 3,244,323$ & $\$ 50,033$ \\
\hline Blended Rate of Electricity (\$/kWh) & $\$ 0.109$ & $\$ 0.132$ & $\$ 0.138$ & $\$ 0.0925$ & $\$ 0.0922$ & $\$ 0.0762$ \\
\hline Lifecycle Cost of Electricity & $\$ 394,822$ & $\$ 2,134,217$ & $\$ 1,739,395$ & $\$ 75,948,156$ & $\$ 77,137,710$ & $\$ 1,189,554$ \\
\hline
\end{tabular}

Note: If demand charges were only charged based on day-time peak, the load of charging the buses would not add demand charges to the depot's electricity cost. In that scenario, the annual cost of electricity would only increase by $\$ 51 \mathrm{k}$ (not $\$ 90 \mathrm{k}$ ). 


\section{Insights for bus fleet charging}

- Both rate structures include similar energy and demand charges

- Bus charging demand identical in both cases

- Electric bus charging load overshadows existing bus depot load, resulting in significant increase in demand charges.

- University campus load overshadows charging load, resulting in zero increase in demand charges.

- Whether or not EV chargers can be placed behind building load on the same meter greatly impacts potential costs.

- Giving charging station owners the ability to select the rate structure that suits their situation could encourage charging station deployment. 
8. Insights (Recap)

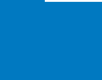

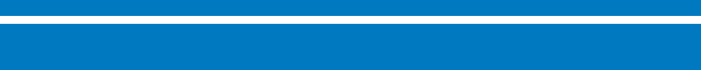




\section{Insights}

- What EV charging behaviors might systematically increase or decrease the utility's cost of service in Colorado?

- Charging during periods with low system cost

- The ability to vary charging load up or down in the evening to balance load and maintain system stability

- How would load profiles change if they reflected reasonably achievable behaviors that reduced the cost of service?

- TOU rates would likely mitigate peak load growth by shifting charging load to low-cost hours

- However, the 9 p.m. TOU transition period could result in a new evening peak as well as a brief but steep demand ramp, if EV charging is not spread out using $D R$ 


\section{System impacts of charging behaviors}

- How would load profiles change if they reflected reasonably achievable behaviors that reduced the cost of service?

- Controlled charging, if used extensively and if EV adoption were high, has the potential to mitigate formation of a new peak under existing TOU rates 


\section{Getting ready}

- Are there "make-ready" investments by the utility that might encourage desirable load growth for EV charging?

- High-density residential buildings (condos and apartments) are a potential focus area where EV demand might currently be suppressed due to the lack of L2 (240v) charging capability

- A review of PUC rules that govern master metering could

- identify possible amendments specific to EV charging in multifamily residences, and

- inform the design of utility programs to target make-ready investments in multifamily developments where the chances of both EV use and cost recovery are high 


\section{At-work charging}

- What effect could electricity rates have on at-work charging?

- At-work charging makes up a small portion of total EV charging, so the system benefits are likely to be small

- Company policies affecting at-work EV charging (free vs fee, open vs assigned spaces) are outside the sphere of electricity rate making 


\section{Thank You}

\section{www.nrel.gov}

NREL/PR-6A20-73303

This work was authored by the National Renewable Energy Laboratory, operated by Alliance for Sustainable Energy, LLC, for the U.S. Department of Energy (DOE) under Contract No. DE-AC36-08GO28308. Funding provided by the Colorado Public Utilities Commission. The views expressed in the article do not necessarily represent the views of the DOE or the U.S. Government. The U.S. Government retains and the publisher, by accepting the article for publication, acknowledges that the U.S. Government retains a nonexclusive, paid-up, irrevocable, worldwide license to publish or reproduce the published form of this work, or allow others to do so, for U.S. Government purposes.

NREL is a national laboratory of the U.S. Department of Energy, Office of Energy Efficiency and Renewable Energy, operated by the Alliance for Sustainable Energy, LLC. 


\title{
Colorado EV Load Model
}

\author{
Additional slides
}




\section{Model methodology - EV load}

- EVI-Pro, a macro-model developed by NREL, supplied an average daily load profile for EV charging.

- EVI-Pro uses a database of recorded vehicle trips from non-EVs to gather data on the driving tendencies of Americans in a typical mid-sized city (Columbus, Ohio). Parameters are then applied to adjust this data to Colorado's context.

- The load data represents a realistic optimization of charging locations and timing based on drivers' pre-existing routes (i.e. charge at home over night, charge at a public charger when shopping, charge at a DCFC when on a road-trip). 


\section{System load data}

- 24-hour load profiles for PSCo balancing authority area, averaged by year

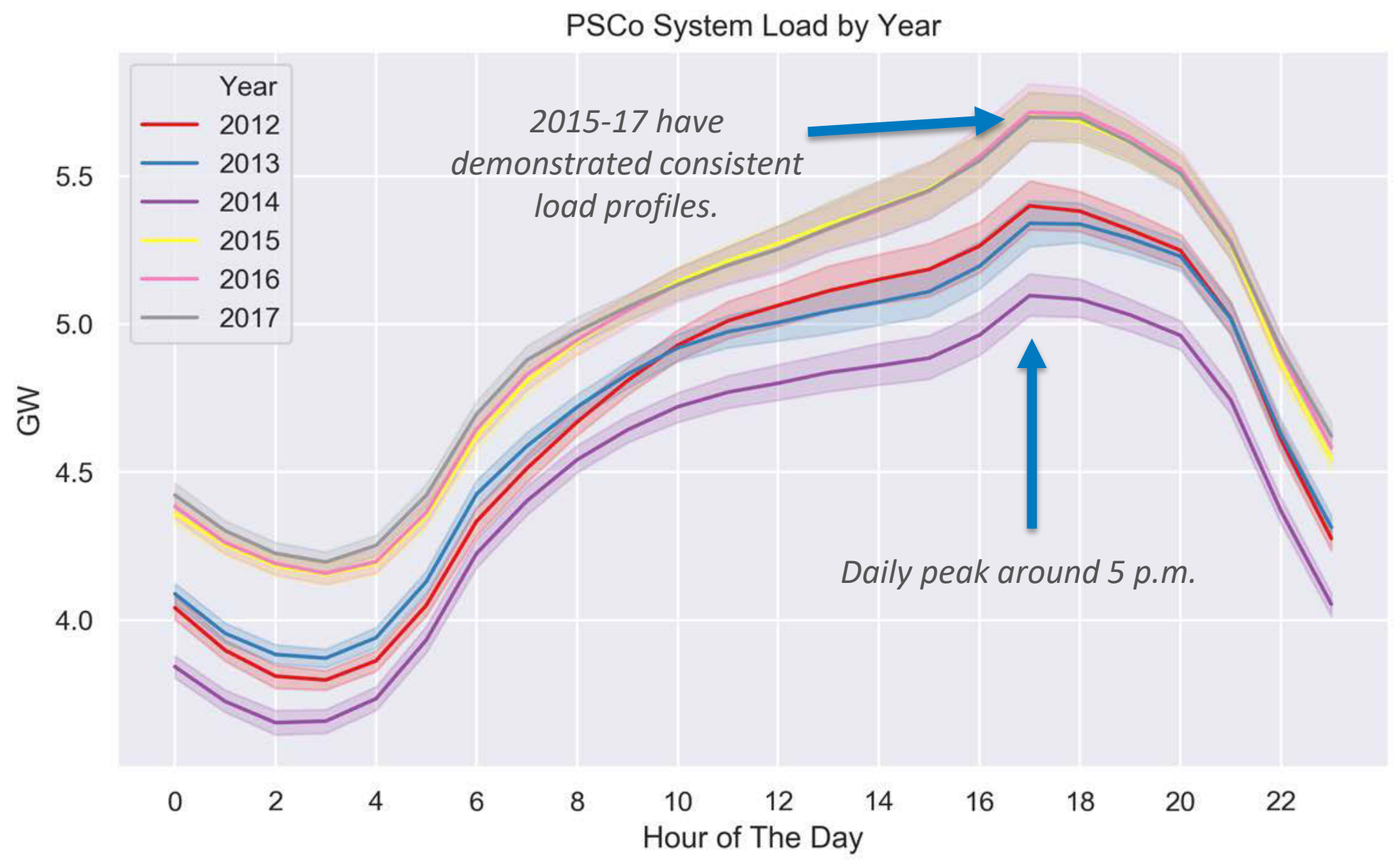

Source: Xcel Energy, FERC Form 714 for PSCo balancing authority area 


\section{System cost data (lambda)}

- 24-hour cost profiles for PSCo balancing authority area, averaged by year

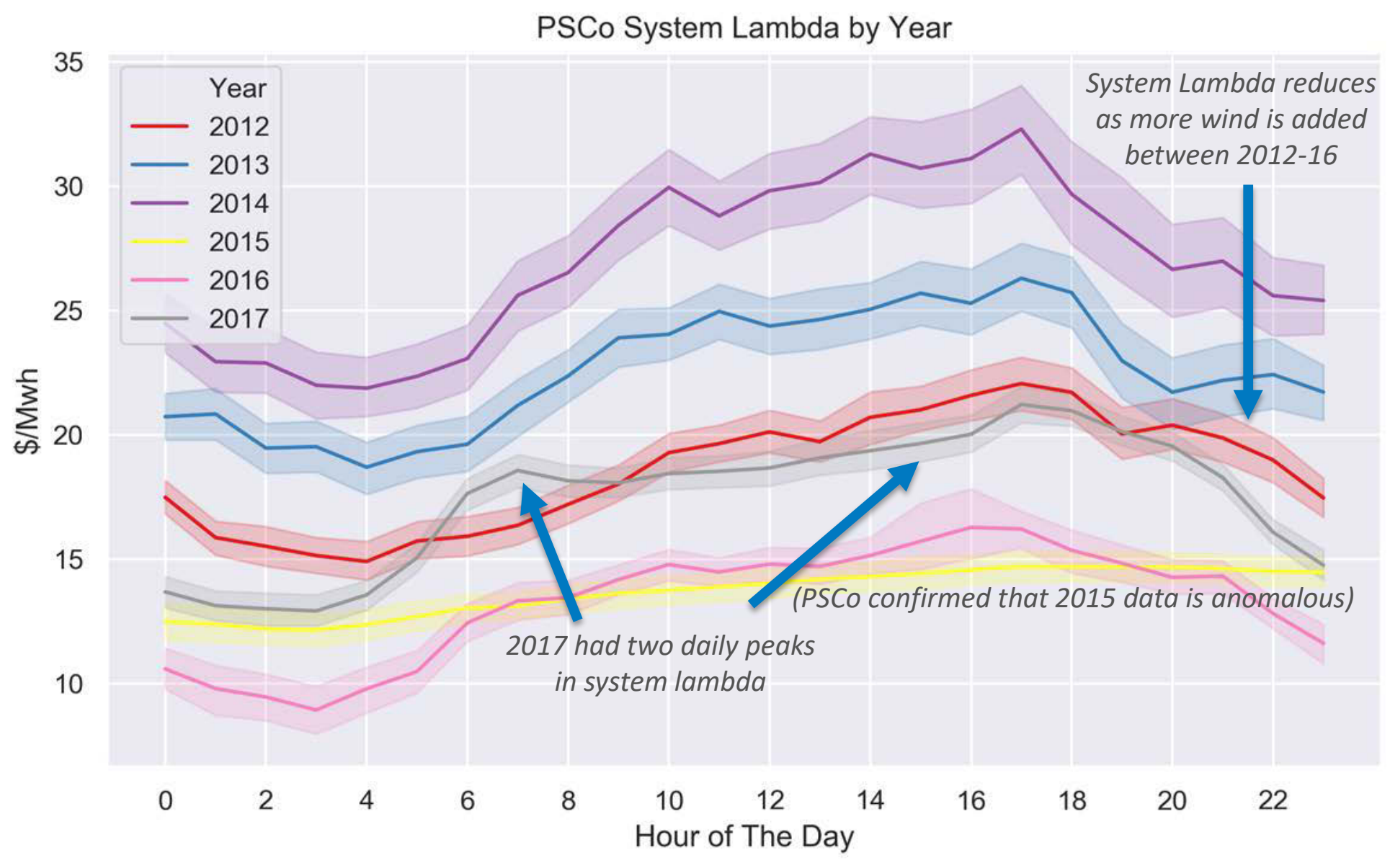

Source: Xcel Energy, FERC Form 714 for PSCo balancing authority area 


\section{Representative wind data}

- Using measured wind data from NREL's Wind Toolkit, we examined 5minute wind profiles from two modeled sites close to the new Rush Creek wind farm.

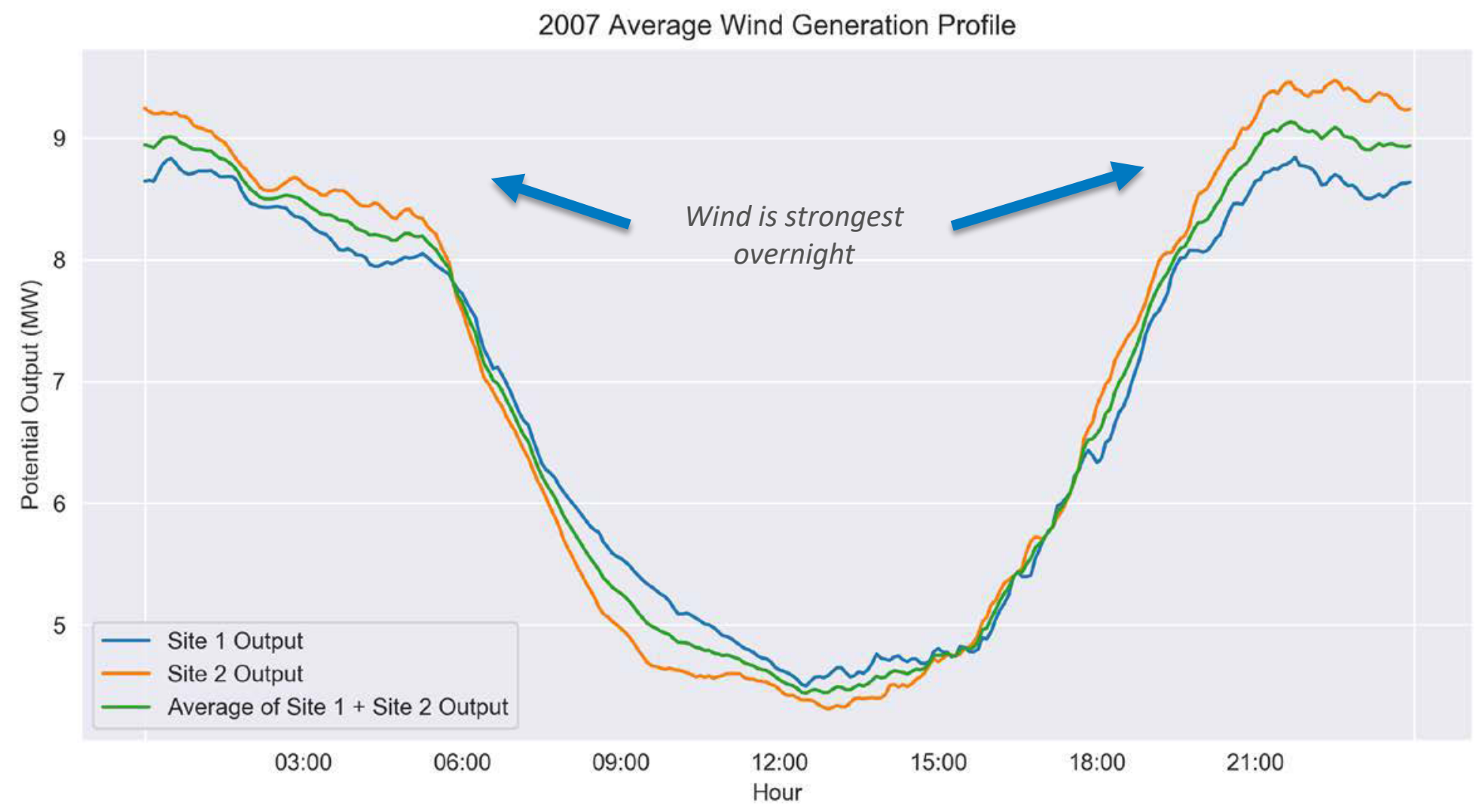




\section{Colorado wind, system costs, and EV charging}

- Wind tends to increase during the hours before and after sunset:

- Opposite the pattern of California solar (diminishes as load increases)

- Highest wind output coincident with EV charging during the evening

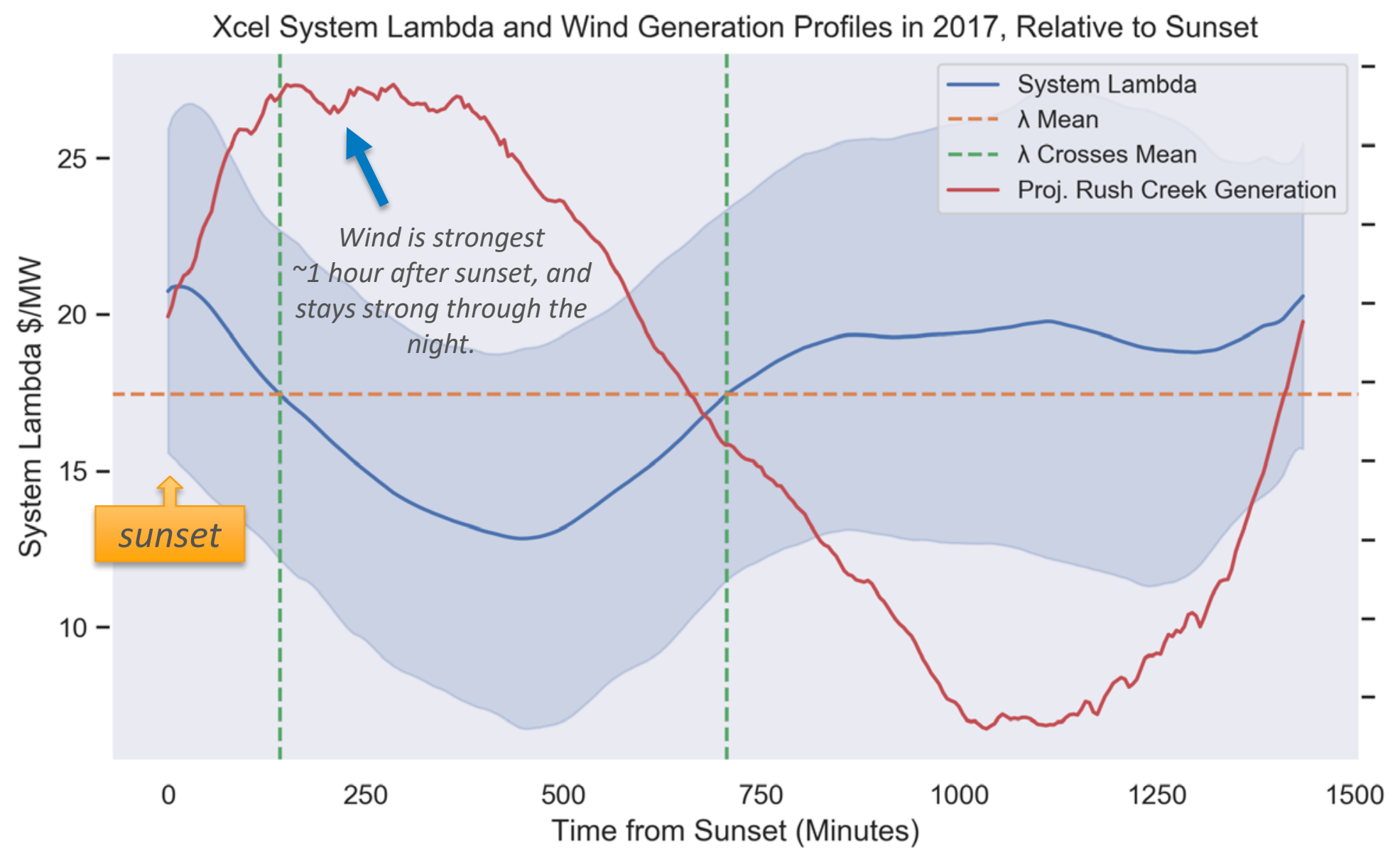




\section{Data trends}

- PSCo's system load has been consistent in shape and magnitude between 2015-17, peaking at around 5 pm.

- The marginal cost of energy is generally trending downwards as more renewables are brought online, although it is potentially becoming 'peakier'.

- Wind output from Xcel's new Rush Creek development will likely be strongest overnight (9PM - 3AM), although strong ramps are likely to occur between 4PM to 8PM. 


\section{Model methodology}

- The seasonality of wind and system lambda were explored, again relative to sunset. Winter offers the longest duration of overnight wind. Winter and spring also have a secondary morning peak in system lambda after sunrise.

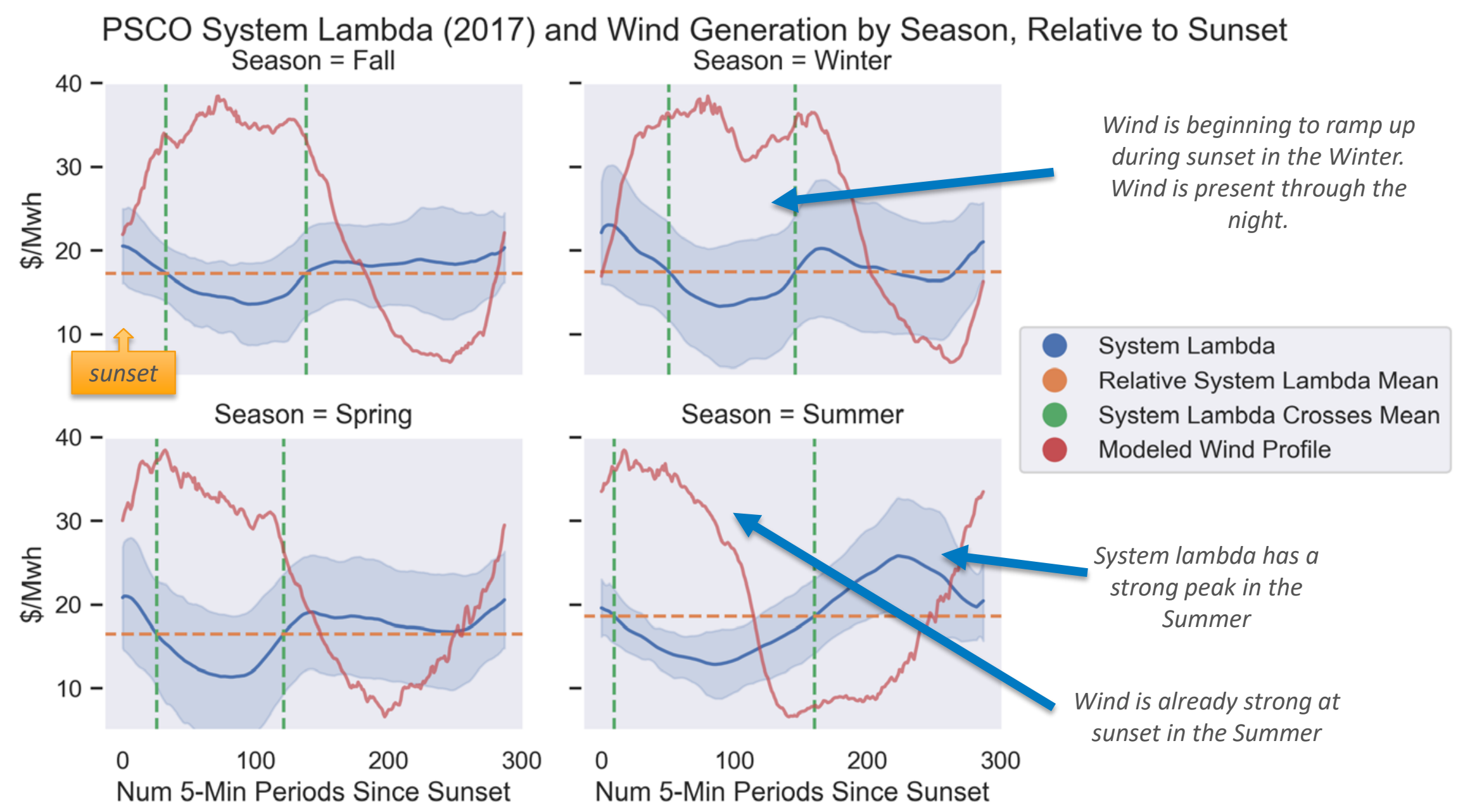




\section{Model methodology}

- Using PSCo's load data from 2017 and the estimated EV charging loads from EVI-Pro, we sought to create a flexible model to explore various scenarios of EV adoption and charging behavior.

- The user inputs parameters such as the number of EVs and the percentage of EV owners who charge under various behavioral constructs (i.e. 'no delay', 'TOU subscriber', etc.).

- Recognizing the significant ramping of wind resources during the evening and night, we modeled a 'shiftable' charging behavior that represents EV charging as highly-flexible demand response (i.e. leave your EV plugged in overnight and the utility will charge it when system lambda is the lowest, or to respond to wind ramping).

- The model optimizes demand response charging by choosing to charge EVs at home when system lambda is the lowest. 


\section{Model methodology}

- We examined eight scenarios based on scenarios outlined by the Colorado Energy Office.

\begin{tabular}{|c|c|c|}
\hline Number of EVS & Charging Behavior & Description \\
\hline \multirow{4}{*}{$\begin{array}{c}\text { CEO Medium } \\
2030 \text { Adoption }(302,429 \mathrm{EVs})\end{array}$} & $\begin{array}{l}100 \% \text { No Delay (all immediate on- } \\
\text { demand charging) }\end{array}$ & Business as usual \\
\hline & $50 \%$ No Delay / 50\% TOU & $\begin{array}{l}\text { Moderate utilization of existing } \\
\text { TOU rates }\end{array}$ \\
\hline & $\begin{array}{l}50 \% \text { No Delay / } \\
50 \% \text { Demand Response }\end{array}$ & $\begin{array}{l}\text { Moderate utilization of } \\
\text { controllable charging }\end{array}$ \\
\hline & $\begin{array}{l}\text { 34\% No Delay / 33\% TOU / } \\
\text { 33\% Demand Response }\end{array}$ & Split between various programs \\
\hline \multirow{4}{*}{$\begin{array}{c}\text { CEO High } \\
2030 \text { Adoption }(940,000 \mathrm{EVs})\end{array}$} & 100\% No Delay & BAU with high EV adoption \\
\hline & $50 \%$ No Delay / 50\% TOU & $\begin{array}{l}\text { High utilization of existing TOU } \\
\text { rates }\end{array}$ \\
\hline & $\begin{array}{l}50 \% \text { No Delay / } \\
50 \% \text { Demand Response }\end{array}$ & $\begin{array}{l}\text { High utilization of controllable } \\
\text { charging }\end{array}$ \\
\hline & $\begin{array}{l}\text { 34\% No Delay / 33\% TOU / } \\
\text { 33\% Demand Response }\end{array}$ & Split between various programs \\
\hline
\end{tabular}




\section{No-delay scenarios (BAU)}
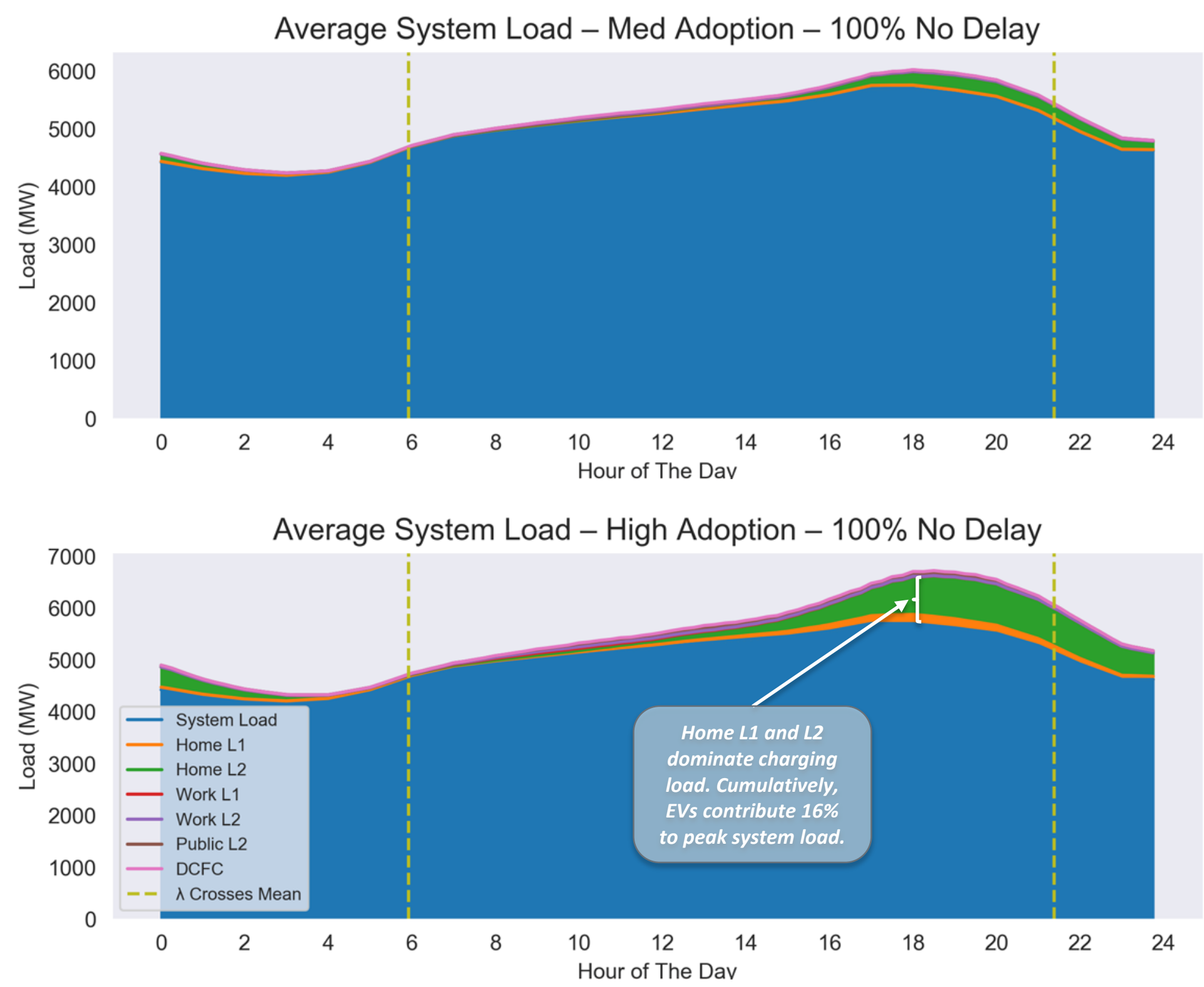


\section{No delay / TOU scenarios}

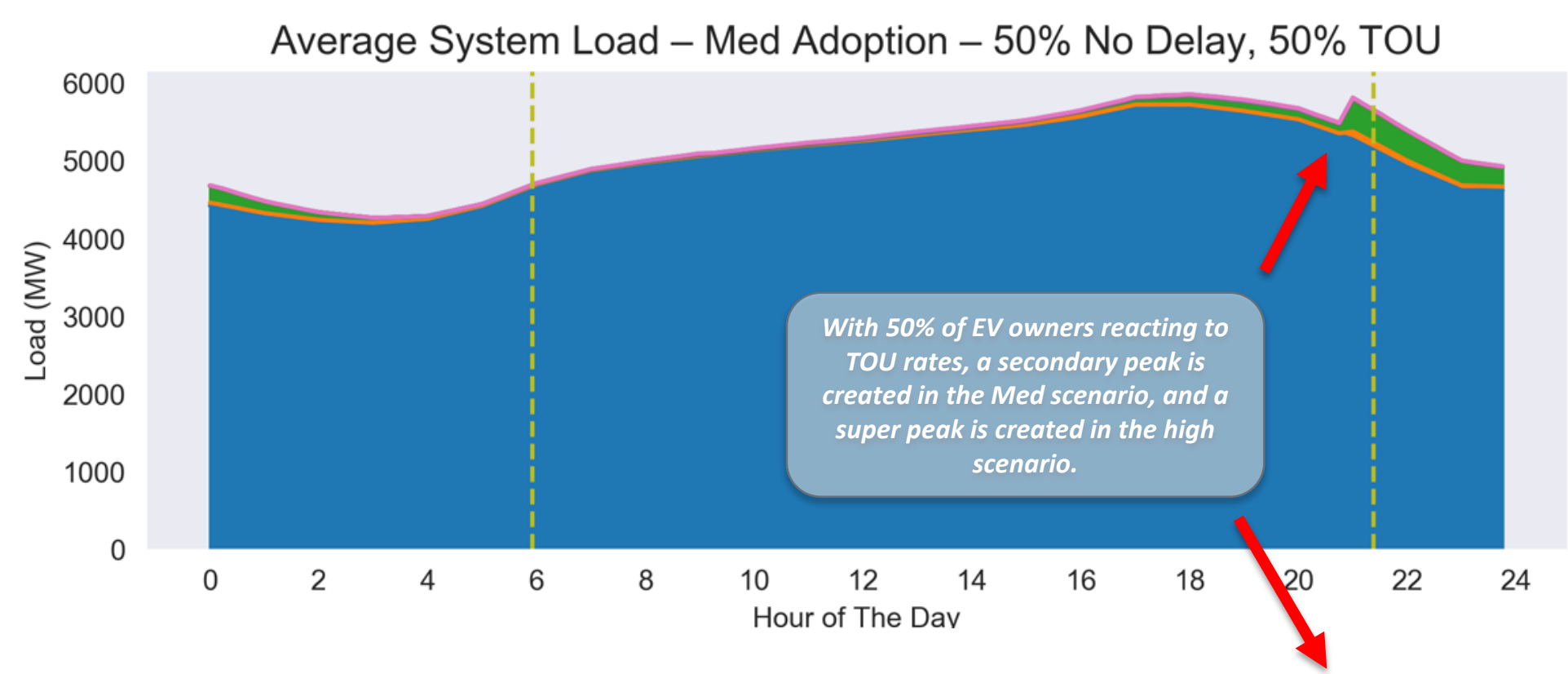

Average System Load - High Adoption - 50\% No Delay, 50\% TOU

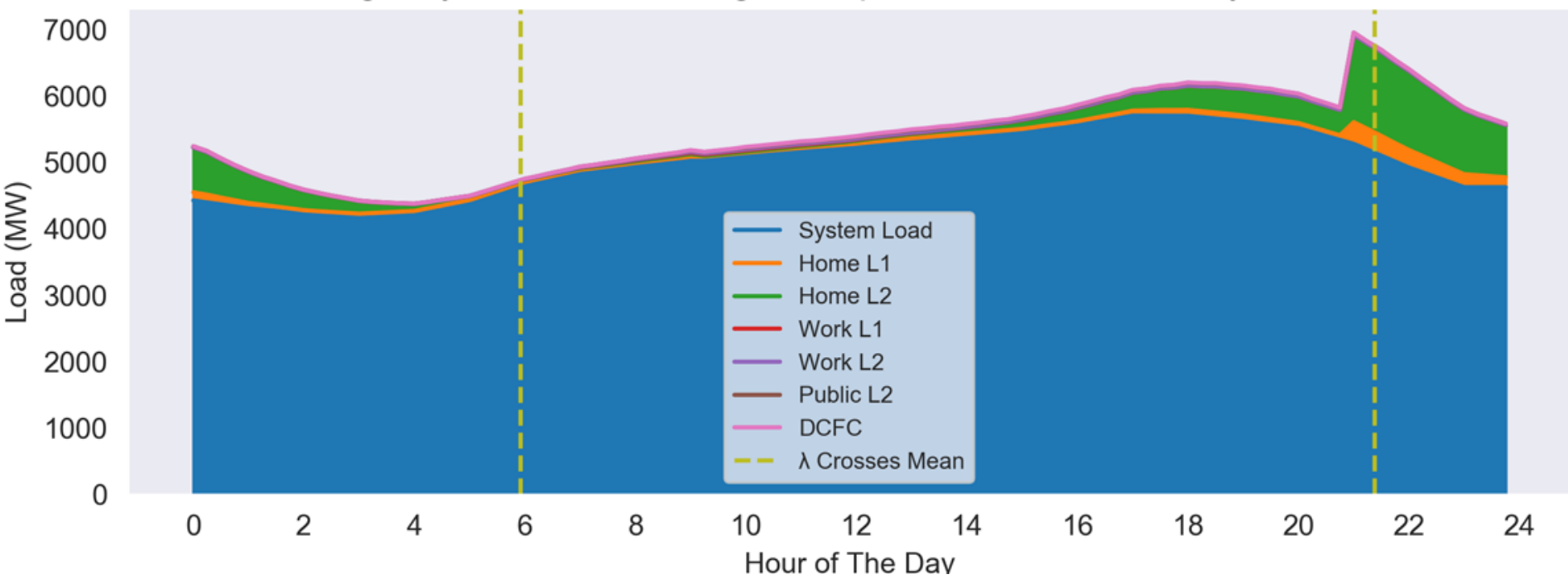




\section{No delay / TOU scenarios}

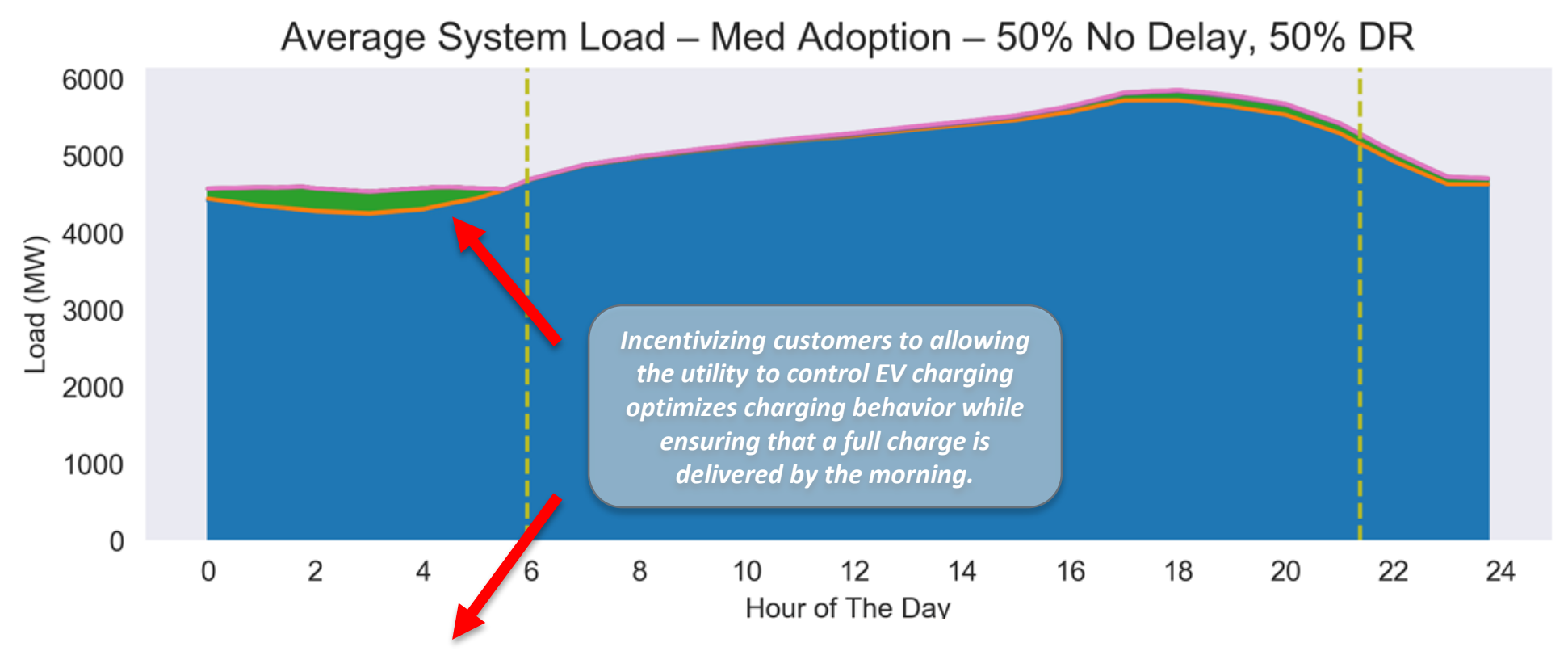

Average System Load - High Adoption - 50\% No Delay, 50\% DR

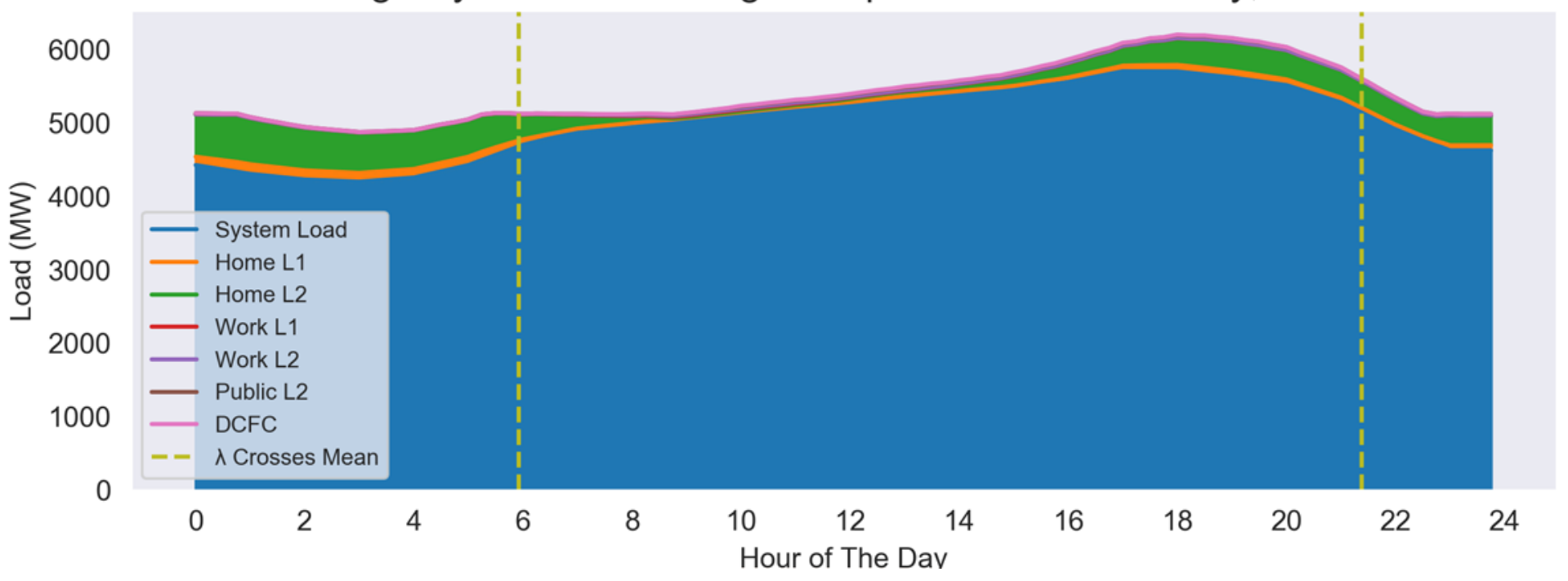




\section{No delay / TOU / demand response scenarios}

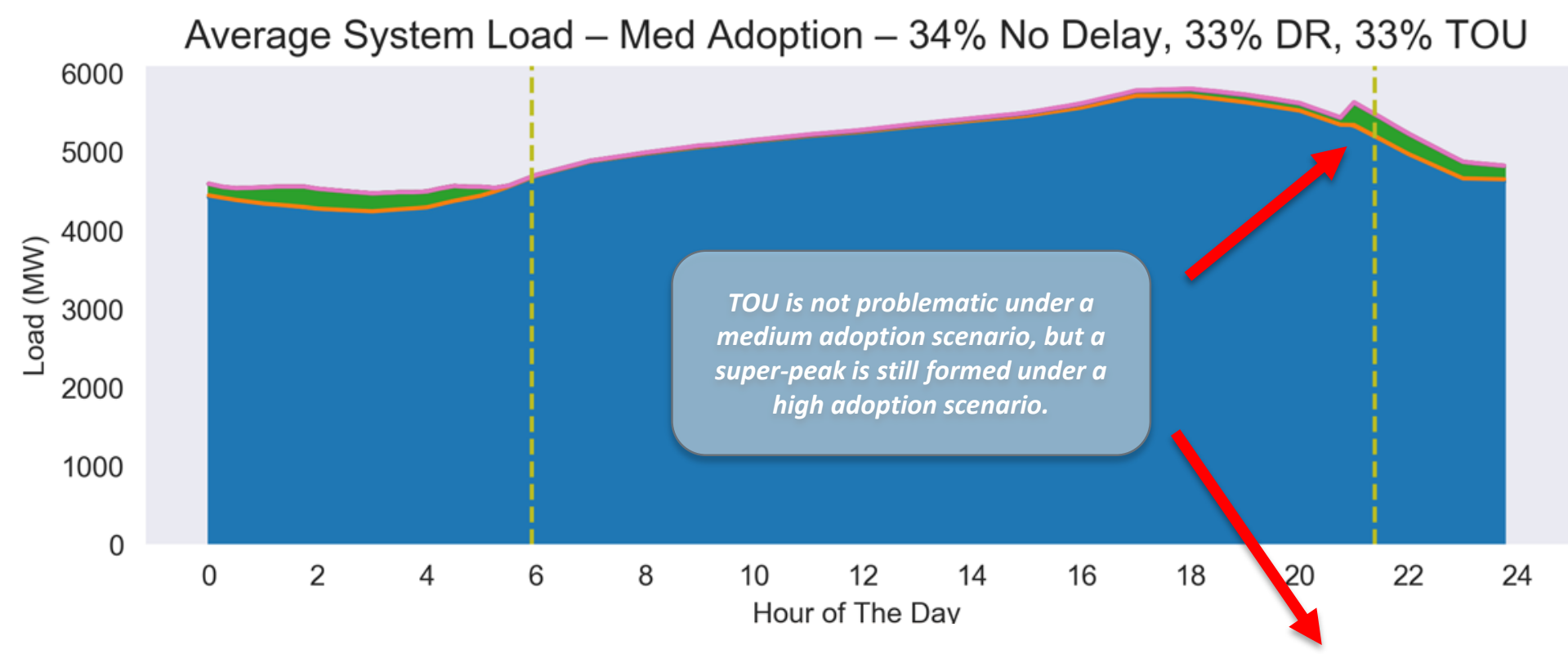

Average System Load - High Adoption - 34\% No Delay, 33\% DR, 33\% TOU

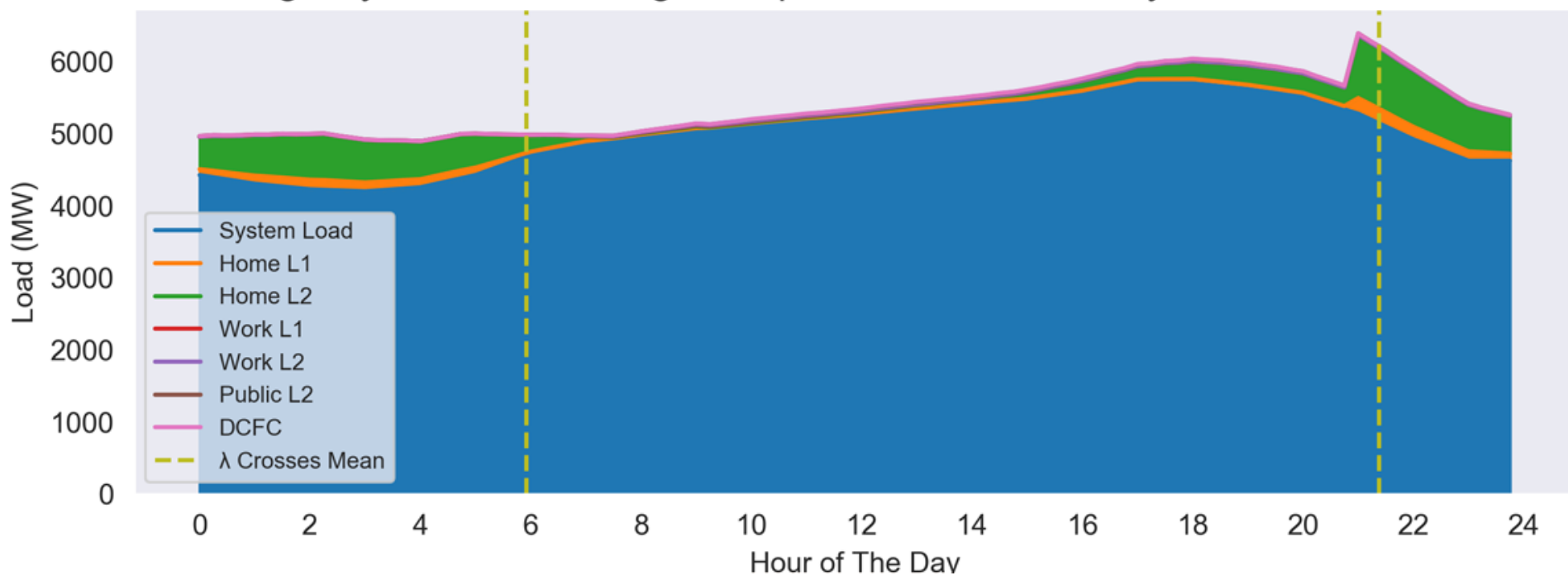




\section{Charging by location}

- In the $100 \%$ No Delay Scenarios, $82 \%$ of EV charging occurs at home, $6 \%$ at work, $11 \%$ at public chargers, and $2 \%$ through DCFC.

- In the No Delay / TOU / DR Scenarios, $93 \%$ of EV charging occurs at home, $2 \%$ at work, $4 \%$ at public chargers, and $1 \%$ through DCFC.

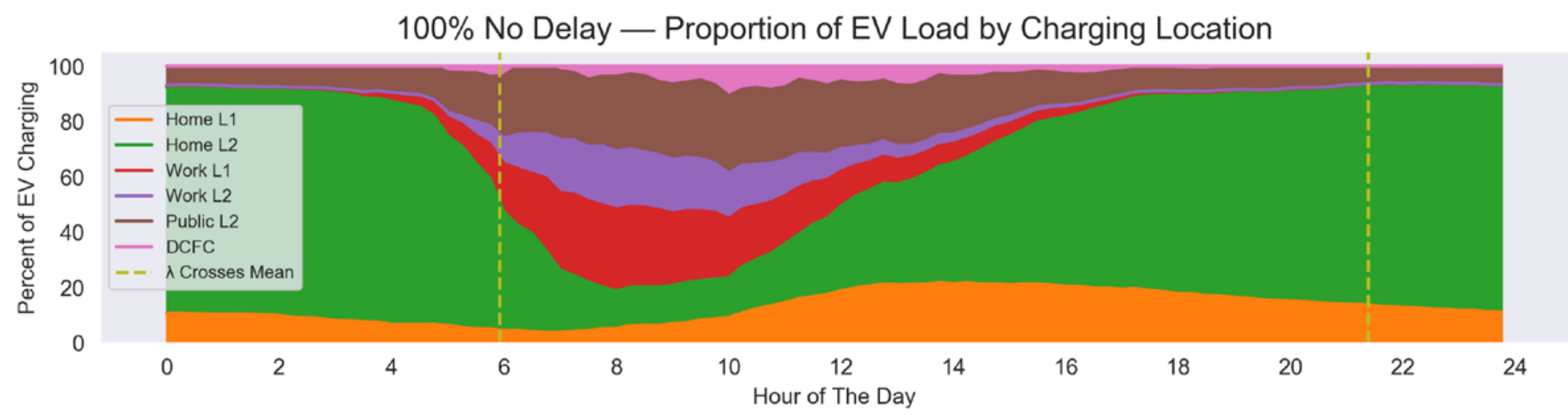

$34 \%$ No Delay, 33\% DR, 33\% TOU — Proportion of EV Load by Charging Location

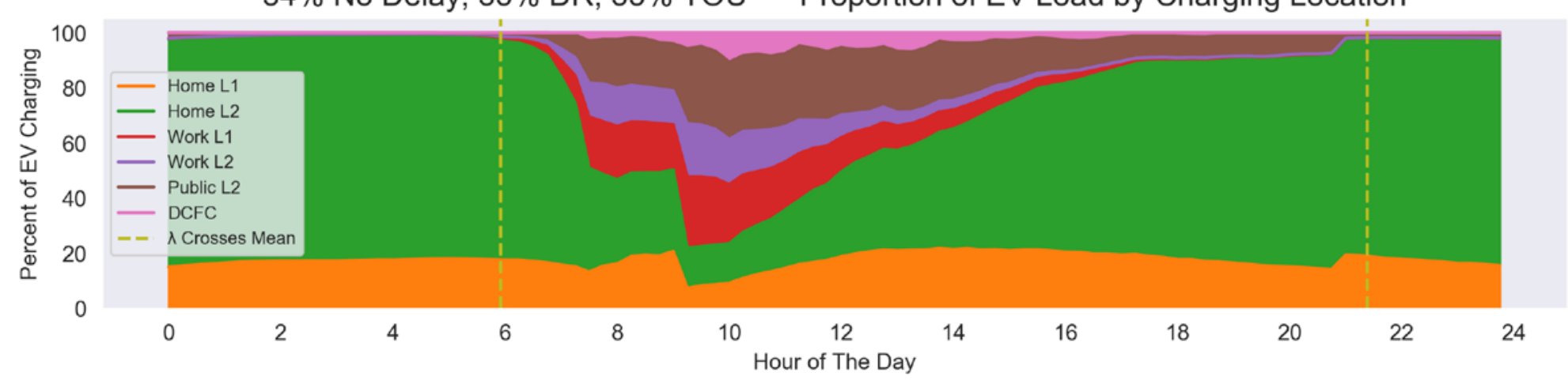




\section{Testing user-defined scenarios}

- An interactive version of the model with adjustable parameters has been hosted online.

- Feel free to enter your own scenarios and study the visualizations in more detail.

- The model is available here: https://mybinder.org/v2/gh/skoeb/CO-EVModel/master?filepath=CO\%20EV\%20Model.i pynb

(this launches a virtual machine, which might take a minute to boot up. Once the model has opened, click on 'Cell > Run All' to initialize the script'.

- $\quad$ Please contact Sam.Koebrich@NREL.gov with any questions or issues with this version of the model.

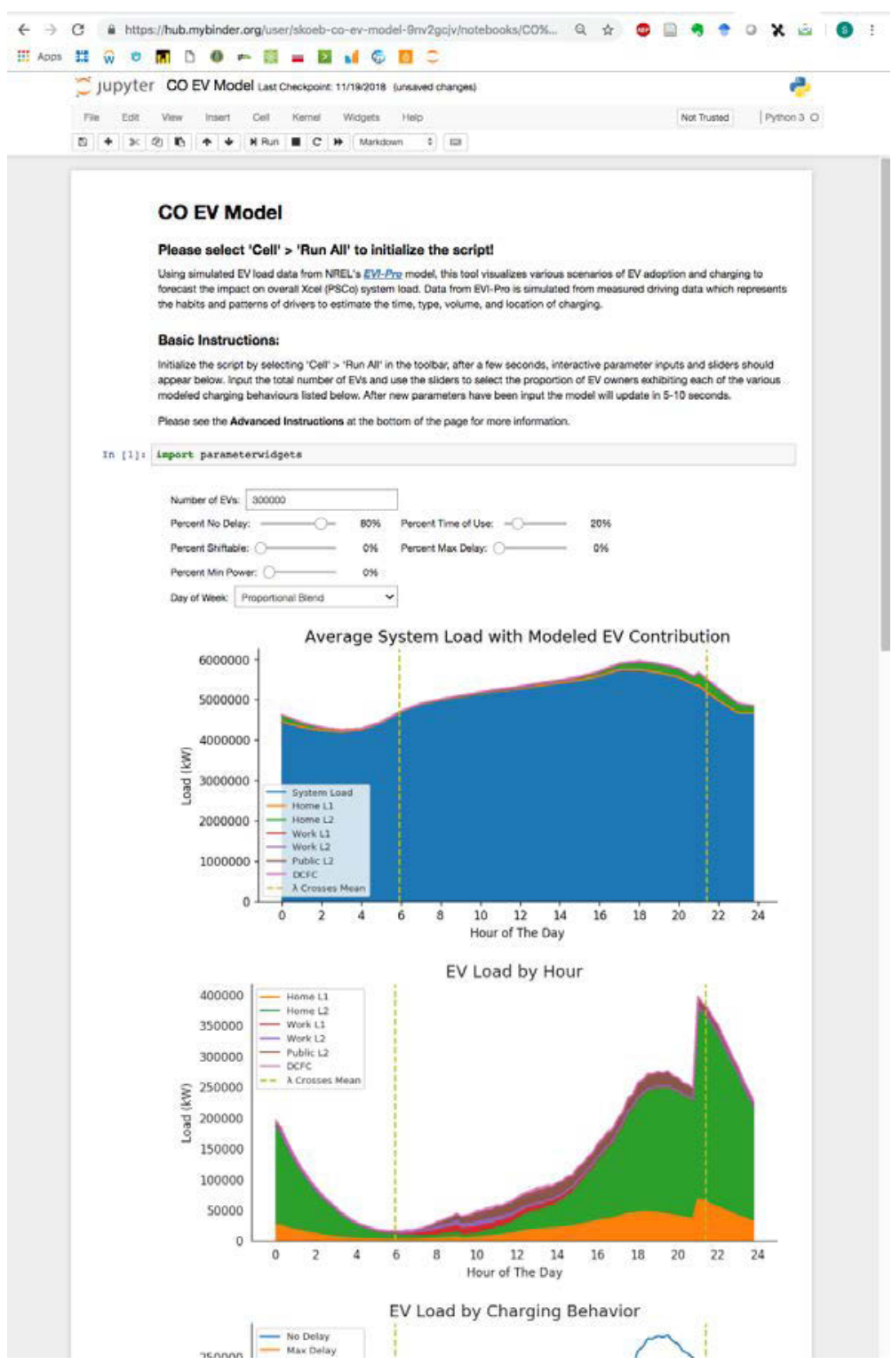


References 


\section{References}

- $\quad$ Bauman, J., Stevens, M.B., Hacikyan, S., Tremblay, L. Mallia, E., and C.J. Mendes. 2016. "Residential Smart-Charging Pilot Program in Toronto: Results of a Utility Controlled Charging Pilot." World Electric Vehicle Journal 8, no. 2: 531-542. https://www.mdpi.com/2032-6653/8/2/531

- $\quad$ BCS Incorporated. 2015. "Electric Vehicle Market Implementation Study." https://www.colorado.gov/pacific/energyoffice/atom/14086

- Bloomberg New Energy Finance. 2017. "U.S. Utilities Offer Multiple Electric Car Charging Rates." https://about.bnef.com/blog/u-s-utilities-offer-multiple-electric-car-charging-rates

- $\quad$ The Brattle Group. 2017. "The National Landscape of Residential TOU Rates."

http://files.brattle.com/files/12658 the national landscape of residential tou rates a preliminar y summary.pdf

- $\quad$ California Independent System Operator (CAISO). 2019. "Today's outlook: Net demand (demand minus solar and wind). Web portal of current system conditions, Jan. 24.

http://www.caiso.com/TodaysOutlook/Pages/default.aspx

- Colorado Energy Office (CEO). 2015. "Electric Vehicle Market Implementation Study." https://www.colorado.gov/pacific/sites/default/files/atoms/files/EV\%20Market\%20Study\%202015 0 .pdf

- $\quad$ Draxl, C., B.M. Hodge, A. Clifton, and J. McCaa. 2015. "The Wind Integration National Dataset (WIND) Toolkit." Applied Energy 151: 355366.

- $\quad$ Electrify America. 2018. Conversation between authors and Michael Tubman.

- $\quad$ El Paso Electric. 2018. Data provided to authors by Antonio Reyes.

- $\quad$ Energetics Incorporated. 2015. "Electricity Rate Tariff Options for Minimizing Direct Current Fast Charger Demand Charges." https://www.nyserda.ny.gov//media/Files/Publications/Research/Transportation/Electricity-Rate-Tariff-Options.pdf 


\section{References}

- Fleet Carma. 2016. "Residential Smart Charging Pilot in Toronto: Results of a Utility Controlled Charging Pilot." https://www.fleetcarma.com/resources/chargeto

- Hanlin, J., Reddaway, D. and J. Lane. 2018. "Battery Electric Buses: State of the Practice."Transit Cooperative Research Program. http://www.trb.org/Publications/Blurbs/177400.aspx

- Local Government Commission, Redwood Cost Energy Authority, Schatz Energy Research Group and Siskiyou County Economic Development Council. 2018. "Electric Vehicle Charger Selection Guide."

https://afdc.energy.gov/files/u/publication/EV Charger Selection Guide 2018-01-112.pdf

- Mitchem, S. 2015. "Frito-Lay Electric Vehicle Fleet: Fast Responding Regulation Service." http://www.ercot.com/content/wcm/key documents lists/53418/5. FRRS Frito Lay 021920 15 revised.pdf

- Muratori, M., Elggvist, E., Cutler, D., Eichman, J., Salisbury, S., Fuller, Z. and J. Smart. Forthcoming. "Technology Soluntions to Mitigate Electricity Cost for Electric Vehicle DC Fast Charging. Golden: National Renewable Energy Laboratory.

- Nexant. 2014. "Final Evaluation of SDG\&E Plug-in Electric Vehicle TOU Pricing and Technology S tudy." https://www.sdge.com/sites/default/files/SDGE\%20EV\%20\%20Pricing\%20\%26\%20Tech \%20Study.pdf 


\section{References}

- O'Connor, P. and M. Jacobs. 2017. “Charging Smart: Drivers and Utilities Can Both Benefits from Well-Integrated Electric Vehicles and Clean Energy." Union of Concerned Scientists. https://www.ucsusa.org/sites/default/files/attach/2017/05/Charging-Smartfull-report.pdf

- $\quad$ Pelletier, S., Jabali, O. and Laporte, G. 2018. "Charge scheduling for electric freight vehicles." Transportation Research Part B: Methodological. Vol. 115: 246-269. https://www.sciencedirect.com/science/article/pii/S0191261517308871

- Schücking, M., Jochem, P., Fichtner, W., Wollershiem, O. and K. Stella. 2017. "Charging strategies for economic operations of electric vehicles in commercial applications." Transportation Research Part D. Vol. 51:173-189. https://www.sciencedirect.com/science/article/pii/S1361920915301358

- Smart Electric Power Alliance. 2017. "Utilities and Electric Vehicles: The Case for Managed Charging." https://sepapower.org/resource/ev-managed-charging

- U.S. Department of Energy. 2019. "Alternative Fuels Data Center: Electric Vehicle Charging Station Locations." Accessed February 1, 2019 from: https://afdc.energy.gov/fuels/electricity locations.html

- Whited, M., Allison, A., and R. Wilson. 2018. "Driving Transportation Electrification Forward in New York." Synapse Energy Economics. http://www.synapseenergy.com/sites/default/files/NY-EV-Rate-\%20Report-18-021.pdf

- Wood, E. and C. Rames. 2017. "Electric Vehicles in Colorado: Anticipating Consumer Demand for Direct Current Fast Charging." Golden: National Renewable Energy Laboratory. https://www.nrel.gov/docs/fy17osti/68447.pdf

- Xcel Energy. 2017. "FERC Form 714." 